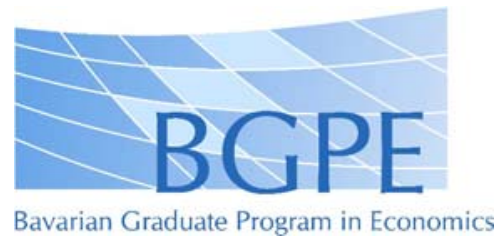

BGPE Discussion Paper

No. 11

\title{
The Effect of Mergers on the Incentive to Invest in Cost Reducing Innovations
}

\author{
Robin Kleer
}

December 2006

ISSN 1863-5733

Editor: Prof. Regina T. Riphahn, Ph.D.

Friedrich-Alexander-University Erlangen-Nuremberg

(c) Robin Kleer 


\title{
THE EFFECT OF MERGERS ON THE INCENTIVE TO INVEST IN COST REDUCING INNOVATIONS
}

\author{
by \\ Robin Kleer \\ University of Würzburg
}

This version

December 20, 2006

\begin{abstract}
Both mergers and innovation are central elements of a firm's competitive strategy. However, model-theoretical analysis of the merger-innovation link is sparse. The aim of this paper is to analyze the impact of mergers on innovative activities and product market competition in the context of incremental process innovations. Inefficiencies due to organizational problems of mergers are accounted for. We show that optimal investment strategies depend on the resulting market structure and differ significantly from insider to outsider. In our linear model mergers turn out to increase social surplus.
\end{abstract}

Keywords: Horizontal mergers, innovation, research joint venture, market structure

JEL: L13, L22, G34, O31

\section{Acknowledgement}

I am grateful to Norbert Schulz for continuous guidance, encouragement and assistance. I would also like to thank Peter Welzel and seminar participants at the University of Würzburg and the $2^{\text {nd }}$ BGPE research workshop for helpful comments. 


\section{Introduction}

Mergers and acquisitions are instruments for the growth, diversification and rationalization of companies. Innovation is a way for firms to achieve and maintain a competitive advantage. So both these elements are fundamental to a firm's competitive strategy. To improve our understanding of firms' investment decisions and cooperations it is therefore necessary to comprehend the interdependencies between these important factors.

Moreover, the approval process of mergers is more and more influenced by the impact of mergers on the innovative activities in the market. Mergers are typically considered to harm consumers. Farrell and Shapiro (1990) show in a Cournot oligopoly that for a merger to reduce prices and thus to increase consumer surplus considerable synergies are required. Diffusion of know-how and economies of scale and scope in R\&D are typical elements of efficiency defenses of mergers (Röller, Stennek, Verboven, 2000). Gilbert and Tom (2001) claim that innovation concerns in merger cases rose significantly in the last decades. However, they argue that it is difficult to asses the immediate impact of innovation on the approval process in these cases. This is at least partly caused by the several opposing effects of mergers on innovation incentives. Katz and Shelanski (2004) argue that innovation - as one of the most important drivers of economic welfare - must be considered when deciding about the approval of a proposed merger. They distinguish between the "innovation incentives" criterion, i.e. how the merger changes the incentives to innovate and the "innovation impact" criterion, i.e. how is the effect of innovation on the market, especially comparing the situation before and after the merger. Katz and Shelanski argue that both the effect from market structure on innovation and the backwards effect from innovation on market structure are important in the analysis.

The interdependencies of mergers and innovation have a widespread effect on a firm's strategy. A merger changes the market structure as firm size and concentration is typically increased. This leads to different output levels of firms which in turn influence the firm's investment decisions. Furthermore, the innovation market itself may be affected by the merger. Fewer competitors may increase the probability to win a patent race and lead to more investments. On the other hand, the reduced competitive pressure may lead to a reduction in innovation. Another important effect of mergers is the restructuring process. To capture potential synergies in the innovation sector, R\&D departments have to be reorganized which may lead to personnel problems caused by fear of dismissals, loss of key researchers and 
changes in the organization structure. Finally, the innovative ability of a firm may be a direct reason for a merger. Firms can substitute own R\&D by the acquisition of other companies.

This complexity may be a reason why model-theoretical analysis of the merger-innovation link is sparse. However, if the analysis is focused on certain sub aspects important conclusions can be drawn. Banal-Estanol et al. (2004) use a 3 stage game model with 3 firms to deduct incentives to merge and to innovate in a Cournot market. They analyze situations with and without internal conflict where firms can either invest or not invest in a cost reduction. Their focus is on the internal organization of a firm and the stability of mergers. In contrast to Banal-Estanol et al. (2004) we analyze exogenous mergers and focus on incentives to innovate. Moreover, we do also allow for asymmetric situations after the merger. Jost and van der Velden (2006) analyze mergers in a patent contest model and show that a merger can be beneficial to the merging firms even if synergetic effects are rather low. However, their model fully concentrates on the innovation market as the winner of the patent race is awarded a monopoly profit in the output market. In contrast, we model both competition in the innovation and in the output market. Other theoretical papers on mergers and innovation rather establish rules of thumb or guidelines for analyzing mergers in an innovation context (see for example Katz and Shelanski, 2004).

Empirical work on this subject can be grouped in two categories: Organizational issues and strategic aspects. The organizational literature deals with the effect of mergers on $R \& D$ employees and the internal organization of R\&D. Bommer and Jalajas (1999) show that even only the threat of organizational downsizing can have a negative impact on the innovative performance, i.e. willingness to make suggestions, risk taking and job motivation. Internal resistance to the merger may lead to several other problems: Communication problems among new fellow employees, denial of products and processes from the other company, the "notinvented-here” syndrome (Katz and Allen, 1982) and agency problems that affect the motivation of researchers (see Cassiman et al., 2005). A study of Ernst and Vitt (2000) shows that almost a third of key inventors, i.e. persons responsible for high quality and high quantity patents, quit the merged company. This behavior often leads to a dramatic reduction in innovative performance. The personnel problem is directly linked to R\&D reorganization. Hagedoorn and Duysters (2000) analyze the impact of organizational differences on the success of mergers. They measure the degree of similarity by the size of companies and find empirical support for their hypothesis that there is a positive relationship between the similarity in size of the companies to merge and the post merger technological performance, measured by total numbers of patents applied for. 
The empirical literature on strategic aspects of mergers deals with the firms' merger and innovation policy and how this policy is influenced by the firm's and competitors' characteristics. Cefis et al. (2005) study the effect of mergers on the optimal mix of investments in product and process innovations. They find empirical support for their hypothesis that firms involved in mergers invest more in product than in process innovations. Furthermore, they find that R\&D efficiency decreases, which is attributed to post-merger integration problems. Gugler and Siebert (2004) analyze the efficiency effects of mergers and R\&D joint ventures with focus on the development of market shares after a merger. They find positive developments of market shares both for mergers and $R \& D$ joint ventures, but stronger and longer lasting effects for joint ventures. However, their study is on the semiconductor industry, which is one of the most R\&D intensive and innovative industries. Hagedoorn and Duysters (2000) analyze the effect of strategic fit of companies, measured by technological and product market relatedness, on the success of a merger and find empirical support for their hypothesis that more related companies show a better technological performance after the merger. This effect is attributed to economies of scale and scope in R\&D. Another strategic aspect of mergers in innovation context is the substitution of own R\&D by the acquisition of R\&D active companies. Dessyllas and Hughes (2005) examine the acquirers of these strategic buys. They assume that firms with lower R\&D input and output are more likely to acquire $R \& D$ active firms, which is supported by their analysis. Moreover, they find empirical evidence of their hypothesis that a certain level of knowledge about technology, measured by stock of patents, is needed to identify potential candidates for acquisition and to use the acquired knowledge efficiently. ${ }^{1}$

It is difficult to identify the main drivers of a successful merger in the R\&D context from these strands of literature as the empirical results lead into different directions and focus on different topics.

The aim of this paper is to analyze the impact of horizontal mergers on the innovative efforts of merging and non-merging firms. Firms compete in innovation activities as well as in product markets. We focus our analysis on the minimal structure that allows for the distinction of merging and non-merging firms, i.e. we start from a market structure with 3 active firms. Depending on the modeling strategy of mergers it is well known that mergers may turn out to be not profitable if innovation is not modeled. In contrast we find that the inclusion of competition in innovative activities renders most mergers profitable. This is a

\footnotetext{
${ }^{1}$ This knowledge level is also called absorptive capacity (see Cohen and Levinthal, 1989).
} 
first result and confirms a result of Jost and van der Velden (2006) in a different modeling context.

In a first step to explore the impact of a merger on innovative activities we ignore any organizational problems of a merger. Using linear demand and cost structures we find that a merger induces higher innovative efforts of the merging firms. In order to test the robustness of this finding - and of the other results - we screen the most popular modeling strategies for mergers. They will be spelled out further below. It turns out that this finding is robust in this respect. However, the impact of a merger on the non-merging firm's incentive to innovate depends on the modeling strategy. The same holds true for the impact of a merger on consumer surplus as well as on social surplus although it is positive in most cases.

In a second step we introduce the organizational problems of a merger by assuming an increased level of $\mathrm{R} \& \mathrm{D}$ costs for the merging firms. This provides a much richer picture where it is not guaranteed that the merging firms' incentive to innovate increases. Whether a merger induces higher incentives to innovate for any of the firms depends on how mergers are modeled as well as on the level of inefficiencies due to the organizational problems. Interestingly, in most cases a merger still increases social surplus.

Innovation is generally considered to be the introduction of new methods, improved versions of former products and processes or completely new inventions. In our paper we focus on process innovations, i.e. a reengineered or newly developed production process aiming at producing goods more efficiently. Additionally, we assume that all knowledge acquired by innovation efforts stays within the company, i.e. that there are no "knowledge spillovers".

We analyze mergers for three popular modeling approaches. We also consider R\&D joint ventures as they are often considered to have the positive synergy effects of a merger without reducing competition in the output market.

Firms play a noncooperative 2 stage game under complete information. In the first stage they decide about their investments in process innovations and by doing so set their marginal costs. In the second stage firms choose quantities. The game is solved by backwards induction. This 2 stage model is similar to a model of R\&D joint ventures by Rosenkranz (2003). However, she focuses on the different external effects of process and product innovation while our focus is on the different effects in several forms of mergers. Furthermore, in her analysis all firms remain competitors in the output market while we allow for mergers.

The benchmark case with 3 identical firms is compared to a situation where 2 firms merge or cooperate on $R \& D$. We do not consider mergers to monopoly or $R \& D$ joint ventures of all firms as these cooperations would lead to no competition in the product or innovation market. 
In the cases of merger, we distinguish three possibilities for the resulting market structure. The first case is the simple closure of one firm. This way of modeling the merger refers to Salant, Switzer and Reynolds (1983) and is therefore denoted as case SSR. The second type refers to Daughety (1990) and models the merged company as a Stackelberg-Leader in the resulting market. This is denoted as case D. Creane and Davidson (2005) propose another way of modeling the merger. The two companies involved in the merger remain separate divisions but set their quantities sequentially. Thus, one division is a Stackelberg-Leader in the intrafirm game. The outsider is aware of the internal structure but treats each of the merged firm's divisions as a Cournot competitor. This case is referred to as case $\mathrm{CD} .^{2}$ Finally, the results of an R\&D joint venture are analyzed (case JV). We derive optimal investment strategies and quantities and the resulting profits. In order to analyze the impact of our model parameters we calculate some comparative statics. Our results show that optimal investment strategies depend on the resulting market structure and differ significantly from insider to outsider. In some settings mergers are profitable while in other settings outsiders benefit from mergers. The effect on consumer welfare, measured by total output, depends on the resulting market structure. The impact of innovation costs on profits is also ambiguous. We show that some firms prefer low innovation costs while others benefit from increasing innovation costs. This effect is due to the strategic aspect of investment in innovation.

The paper is organized as follows. In section 2 we describe our model and analyze the impact of mergers on innovation and product markets, ignoring inefficiencies due to organizational problems. We also report some results on comparative statics. Section 3 introduces efficiency losses of the combined $R \& D$ department due to internal organization problems. Section 4 concludes, discusses limitations of our model and points out interesting topics for further research.

\section{Model}

There are 3 (a priori identical) firms with homogenous products facing a linear inverse demand function: $p=1-X$ with $X=\sum x_{i}$. This demand can be derived using a representative consumer with utility function $U(x, y)=x-\frac{1}{2} x^{2}+y$, with $y$ being a numeraire good. In addition to the typical possibility to choose output strategically, firms can

\footnotetext{
${ }^{2}$ Huck, Konrad and Müller (2003) provide similar arguments for modeling horizontal mergers that way and derive comparable results. However, their argumentation is a bit different as they use an endogenous timing approach. In our setup, there is no preference for either of these two motivations for the internal structure change due to the merger.
} 
influence their marginal costs via process innovations. The costs for these innovations are $K\left(c_{i}\right)=k \cdot\left(c_{i}-c^{0}\right)^{2} \quad 0 \leq c_{i} \leq c^{0}, k>6 / 5 \cdot{ }^{3}$ Without innovation, firms have constant marginal costs $c^{0}<1^{4}$. Firms are assumed to maximize profits $\pi_{i}=\left(p-c_{i}\right) \cdot x_{i}-k \cdot\left(c_{i}-c^{0}\right)^{2}$, i.e. product profitability minus total innovation costs. For simplicity, we assume that firms have no fixed costs. ${ }^{5}$

Investment in innovation is done in stage 1, setting of quantities in stage 2. We assume no discounting between these stages. ${ }^{6}$ This setup is clearly quite special, in particular with respect to the inverse demand functions and the cost structure of the firms. This simplification is done for the ease of calculation and notation. Even in this particular setup differences between the considered market structures become obvious and the effects of a merger or a cooperation differ significantly from insider to outsider.

\subsection{Benchmark Case}

The benchmark case is a simple Cournot game with the additional possibility to invest in process innovations to reduce marginal cost prior to the quantity setting game. Hence, the optimal quantities are

$$
x_{i, B}^{*}=\frac{1-3 c_{i}+c_{j}+c_{k}}{4} .
$$

The profit in the optimum, depending on the marginal costs, is thus

$$
\pi_{i, B}^{*}\left(c_{i}\right)=\left(\frac{1-3 c_{i}+c_{j}+c_{k}}{4}\right)^{2}-K\left(c_{i}\right)=x_{i, B}^{*}\left(c_{i}\right)^{2}-k \cdot\left(c_{i}-c^{0}\right)^{2} .
$$

In the first stage, firms can choose their investment in process innovations. Equation (1) is maximized with respect to marginal costs $c_{i}$ leading to the following first order conditions: ${ }^{7}$

$$
\begin{aligned}
& \frac{\partial \pi_{i, B}^{*}}{\partial c_{i}}=-\frac{6}{16} \cdot\left(1-3 c_{i}+c_{j}+c_{k}\right)-2 k \cdot\left(c_{i}-c^{0}\right) \stackrel{!}{=} 0 \\
& \Leftrightarrow c_{i, B}^{*}=\frac{16 k \cdot c^{0}-3}{16 k-3}
\end{aligned}
$$

Inserting the optimal $c$ in the profit function yields the profit in the optimum:

\footnotetext{
${ }^{3}$ The parameter $k$ has to be that high to assure that innovations are nondrastic in all cases, i.e. to guarantee interior solutions. We derive this barrier in the appendix. In the following, we refer to $k$ as innovation costs while $K(c)$ is called total innovation costs.

${ }^{4}$ The lower bound for these initial marginal costs is dependent on the innovation cost parameter $k$ and is derived in the appendix.

${ }^{5}$ This assumption is not necessary in our model. However, some results concerning changes in total profits may change quantitatively, depending on how the merger or a R\&D joint venture affects fixed costs.

${ }^{6}$ However, the innovation cost parameter $k$ can be reinterpreted to allow for time preferences.

${ }^{7}$ Second order conditions are satisfied here and in all other cases (see appendix).
} 


$$
\pi_{B}^{*}=\left(\frac{1-\frac{16 k \cdot c^{0}-3}{16 k-3}}{4}\right)^{2}-k \cdot\left(\frac{16 k \cdot c^{0}-3}{16 k-3}-c^{0}\right)^{2}=\frac{k \cdot\left(1-c^{0}\right)^{2} \cdot(-9+16 k)}{(3-16 k)^{2}}
$$

The benchmark case is now compared with all merger cases and with a joint venture. Our main focus is the investment in innovations, the total output and the profits of insider and outsider.

Without loss of generality, we assume that firm 1 and 2 cooperate. In cases CD and JV we assume that they have a combined R\&D department leading to identical marginal costs for firm 1 and 2. In this section, we assume that the reduction from two to one R\&D department works without problems. Therefore the merged firm has the same cost function for R\&D as before. We relax this assumption in section 3.

\subsection{Case SSR}

This way of modeling a merger refers to Salant, Switzer and Reynolds (1983). Firm 1 and 2 merge and one of these companies is closed down. In effect, this merger changes the market from a symmetric triopoly to a symmetric duopoly. Thus, the optimal quantities are

$$
x_{i, S S R}^{*}=\frac{1-2 c_{i}+c_{j}}{3},
$$

leading to the profit depending on marginal costs:

$$
\pi_{i, S S R}^{*}\left(c_{i}\right)=\left(\frac{1-2 c_{i}+c_{j}}{3}\right)^{2}-K\left(c_{i}\right)=x_{i}^{*}\left(c_{i}\right)^{2}-k \cdot\left(c_{i}-c^{0}\right)^{2}
$$

Maximizing equation (2) yields the first order conditions:

$$
\begin{aligned}
& \frac{\partial \pi_{i, S S R}^{*}}{\partial c_{i}}=-\frac{4}{9}\left(1-2 c_{i}+c_{j}\right)-2 k \cdot\left(c_{i}-c^{0}\right) \stackrel{!}{=} 0 \\
& \Leftrightarrow c_{i, S S R}^{*}=\frac{9 k \cdot c^{0}-2}{9 k-2}
\end{aligned}
$$

The optimal investment in cost reducing innovations is higher than in the benchmark case leading to lower marginal costs for the SSR firms: $c_{i, S S R}^{*}<c_{i, B}^{*}$. Total innovation costs are better covered with sales due to the increased output level of each individual firm. This result is in accordance with a more general analysis of Vives (2004) that proves in a symmetric market with restricted entry increasing the number of firms tends to reduce R\&D effort. Inserting the optimal $c$ in the profit function yields:

$$
\pi_{S S R}^{*}=\left(\frac{1-\frac{9 k \cdot c^{0}-2}{9 k-2}}{3}\right)^{2}-k \cdot\left(\frac{9 k \cdot c^{0}-2}{9 k-2}-c^{0}\right)^{2}=\frac{\left(c^{0}-1\right)^{2} \cdot k \cdot(-4+9 k)}{(2-9 k)^{2}}
$$


Comparing this profit with the combined profit of firm 1 and 2 in the benchmark case leads to an interesting result. For $k<1.99772$ the profit in the duopoly is higher. ${ }^{8}$ Thus, the additional innovation stage in our model makes a merger profitable for the merging firms if innovation costs are lower than a certain bound. In the original Salant, Switzer and Reynolds (1983) model, a merger of 2 firms without synergies is never profitable. This result is striking as we do not explicitly assume synergies in our model. However, the reduction from two to one $\mathrm{R} \& \mathrm{D}$ department in the merged company can be interpreted as a synergy of this merger. Investment is only made once in the merged company. In the benchmark case, each firm invests in its own cost reduction. Furthermore, each company has a higher output compared to the benchmark case, leading to higher incentives to innovate and an increased profit. The outsider benefits from the merger, as in the Salant, Switzer and Reynolds (1983) model.

Consumer welfare can simply be compared via total quantity, which is larger in the benchmark case. The optimal quantity is influenced by two opposing forces. The reduction from three to two firms increases output per firm but the overall output is decreased. On the other hand, the firms invest more in innovation leading to lower marginal costs. The reason for this increase in investment is the increased output level of each firm. The firms can spread their total innovation costs over more output. The effect of reduced competition in the output market is stronger and thus the total quantity is lower in case SSR.

$$
3 \cdot x_{B}^{*}-2 \cdot x_{S S R}^{*}=3 \cdot \frac{4 \cdot\left(1-c^{0}\right) \cdot k}{16 k-3}-2 \cdot \frac{3 \cdot\left(1-c^{0}\right) \cdot k}{9 k-2}=\frac{6 \cdot\left(1-c^{0}\right) \cdot k \cdot(-1+2 k)}{6-59 k+144 k^{2}}>0 .
$$

Thus, a merger in the SSR case is always beneficial to the outsider, can be beneficial to the insider and is never beneficial to consumers. The effect on social surplus depends on the innovation cost parameter. For low innovation costs $(k<1.56209)$ the effect on social surplus is positive. In this parameter range the merger is beneficial for insider and outsider and the reduction in output is low. If innovation cost are above that bound, the negative effect from consumer surplus dominates and the merger is welfare decreasing.

\subsection{Case D}

In case D two firms merge and become Stackelberg-Leader in the resulting market. Daughety (1990) justifies this way of modeling a merger. An intuitive idea is that the merged company is somehow bigger than the original company and therefore has a special status. Investment in innovation is still simultaneous. ${ }^{9}$ The resulting market structure is thus a Stackelberg market

\footnotetext{
${ }^{8}$ The proof of this and the following statements can be found in the appendix.

${ }^{9}$ If we assume that the merged company is only leader in the innovation market but both firms remain equal competitors in the output market, the leader invests more in R\&D than the follower while both firms invest more
} 
with marginal costs $c_{M}$ for the leader and $c_{O}$ for the follower. This leads to the optimal output

$$
x_{M}^{*}=\frac{1-2 c_{M}+c_{O}}{2}
$$

of the merged company and

$$
x_{O}^{*}=\frac{1-3 c_{O}+2 c_{M}}{4}
$$

of the outsider.

Resulting profits are

$$
\begin{aligned}
& \pi_{I, D}^{*}\left(c_{M}\right)=\frac{\left(1-2 c_{M}+c_{O}\right)^{2}}{8}-K\left(c_{M}\right) \\
& \pi_{O, D}^{*}\left(c_{O}\right)=\frac{\left(1+2 c_{M}-3 c_{O}\right)^{2}}{16}-K\left(c_{O}\right) .
\end{aligned}
$$

These profits are maximized by choosing optimal investments. Differentiating with respect to marginal costs yields the first order conditions:

$$
\begin{aligned}
& \frac{\partial \pi_{I, D}^{*}}{\partial c_{M}}=-\frac{1}{2}\left(1-2 c_{M}+c_{O}\right)-2 k \cdot\left(c_{M}-c^{0}\right)=0 \\
& \frac{\partial \pi_{O, D}^{*}}{\partial c_{O}}=-\frac{3}{8}\left(1+2 c_{M}-3 c_{O}\right)-2 k \cdot\left(c_{O}-c^{0}\right)=0
\end{aligned}
$$

Solving for $c_{M}$ and $c_{O}$ leads to:

$$
\begin{aligned}
c_{M}^{*} & =\frac{3-4 k-13 k \cdot c^{0}+16 k^{2} \cdot c^{0}}{3-17 k+16 k^{2}} \\
c_{O}^{*} & =\frac{3-3 k-14 k \cdot c^{0}+16 k^{2} \cdot c^{0}}{3-17 k+16 k^{2}}
\end{aligned}
$$

The optimal investment of the Stackelberg-Leader is higher than the one of the follower $\left(c_{M}^{*}<c_{O}^{*}\right)$. The leader invests more in cost reducing innovations than the firms in the benchmark case $\left(c_{M}^{*}<c_{B}^{*}\right)$ while the follower invests less $\left(c_{O}^{*}>c_{B}^{*}\right)$.

The insider's profit

$$
\pi_{I, D}^{*}=\frac{\left(-1+c^{0}\right)^{2}(3-4 k)^{2} \cdot k \cdot(-1+2 k)}{\left(3-17 k+16 k^{2}\right)^{2}}
$$

is larger than two times the profit in the benchmark case, while the outsider's profit 


$$
\pi_{O, D}^{*}=\frac{\left(-1+c^{0}\right)^{2}(-1+k)^{2} \cdot k \cdot(-9+16 k)}{\left(3-17 k+16 k^{2}\right)^{2}}
$$

is smaller than the profit of one firm in the benchmark case.

Without the possibility to innovate, all firms are indifferent to the merger, as in this case the combined profit of firm 1 and 2 would equal the merged firm's profit. The same is true for the outsider. ${ }^{10}$ Again the reduction of total innovation costs due to merging and having only one R\&D lab makes the merger profitable. The effect has also a negative influence on the outsider: As the insider can spread his $R \& D$ costs over more output, he invests more in innovation leading to lower marginal costs. The outsider cannot profitably invest that much in innovation. Thus he has higher marginal costs, lower output and a lower profit compared to the benchmark case.

Total output in case D is

$$
X_{D}=x_{M}^{*}+x_{O}^{*}=\frac{2 \cdot\left(1-c^{0}\right) \cdot k \cdot(-5+6 k)}{3-17 k+16 k^{2}}
$$

which is higher than in the benchmark case:

$$
\begin{aligned}
3 \cdot x_{B}^{*}-X_{D} & =3 \cdot \frac{4 \cdot\left(1-c^{0}\right) \cdot k}{16 k-3}-\frac{2 \cdot\left(1-c^{0}\right) \cdot k \cdot(-5+6 k)}{3-17 k+16 k^{2}} \\
& =\frac{2 \cdot\left(-1+c^{0}\right) \cdot k \cdot(-3+4 k)}{-9+99 k-320 k^{2}+256 k^{3}}<0
\end{aligned}
$$

In this setting, the reduction from three to two firms has no effect on total output if all firms don't innovate. Thus, only the effect from innovation remains. This effect has to be analyzed separately for insider and outsider. The insider's optimal investment is higher than in the benchmark case, as analyzed above. This leads to an increase of his output. The outsider is negatively influenced by this reduction of the insider's marginal costs and invests less than in the benchmark case. Therefore, the outsider's output is reduced. But as the insider accounts for a larger proportion of output, the overall output is increased. ${ }^{11}$

Comparing the results with the benchmark case, we see that the merging firms and consumers benefit from the merger while it is never beneficial to the outsider. The surplus of insider and consumers is larger than the profit shortfall of the outsider leading to an increase of social surplus.

\footnotetext{
${ }^{10}$ This can be easily verified looking at the profits of insider and outsider for identical marginal costs and no investment in innovation.

${ }^{11}$ This result is in line with Daughety (1990) who states that mergers and increases in concentration can be socially beneficial if an asymmetric situation occurs.
} 


\subsection{Case CD}

In the CD case, it is assumed that the merged company has two independent divisions. This way of modeling a merger refers to Creane and Davidson (2005). The parent company rewards the manager of each division according to his division's profit. Therefore, both managers set their quantities in order to maximize their division's profit. The multidivisional firm encourages competition across its divisions. ${ }^{12}$ The two companies involved in the merger do not set their quantities simultaneously, but sequentially. Thus, one division is the Stackelberg-Leader in the intra-firm game. As this division's manager is only concerned about his own profit he becomes more aggressive in the market and increases his division's market share. This strategic change of the company's organization leads to an increased market share of the merged company. Investment in innovation is done in order to maximize the joint profit of both divisions. The new technology can be used by both divisions. We call the leader in the merged company division 1, the follower division 2 and the other firm outsider.

The profit of division 2 is given by:

$$
\pi_{D 2}=x_{D 2} \cdot\left(1-x_{D 1}-x_{D 2}-x_{o}\right)-c_{m} \cdot x_{D 2}
$$

Maximizing (3) with respect to $x_{D 2}$ yields the optimal output of division 2 as a function of the leader's and the outsider's output.

$$
x_{D 2}=\frac{1-c_{m}-x_{D 1}-x_{o}}{2}
$$

The leader's profit is thus:

$$
\begin{aligned}
\pi_{D 1} & =x_{D 1} \cdot\left(1-x_{D 1}-x_{D 2}-x_{o}\right)-c_{m} \cdot x_{D 1} \\
& =x_{D 1} \cdot\left(1-x_{D 1}-\left(\frac{1-c_{m}-x_{D 1}-x_{o}}{2}\right)-x_{O}\right)-c_{m} \cdot x_{D 1}
\end{aligned}
$$

Maximizing (5) with respect to $x_{D 1}$ yields

$$
x_{D 1}^{*}=\frac{1-c_{m}-x_{o}}{2}
$$

The outsider's profit is given by

$$
\pi_{O, C D}=x_{o} \cdot\left(1-x_{D 1}-x_{D 2}-x_{o}\right)-c_{o} \cdot x_{o}-K\left(c_{o}\right)
$$

which yields the optimal quantity, depending on the output of division 1 and 2

$$
x_{o}=\frac{1-c_{o}-x_{D 1}-x_{D 2}}{2} .
$$

\footnotetext{
${ }^{12}$ An overview of empirical evidence for this competition in multidivisional firms is given in Creane and Davidson (2005) and in Huck, Konrad and Müller (2003).
} 
Substituting (4) in (7) yields:

$$
x_{o}=\frac{1-2 c_{o}+c_{m}-x_{D 1}}{3}
$$

Solving (7) and (8) for $x_{D 1}$ and $x_{o}$ and inserting the results in (4) we obtain the optimal quantities:

$$
\begin{aligned}
& x_{D 1}^{*}=\frac{2}{5} \cdot\left(1+c_{o}-2 c_{m}\right) \\
& x_{D 2}^{*}=\frac{1}{5} \cdot\left(1+c_{o}-2 c_{m}\right) \\
& x_{o}^{*}=\frac{1}{5}\left(1-4 c_{o}+3 c_{m}\right)
\end{aligned}
$$

Note that for identical marginal costs the outsider's and the follower's quantities are the same. The resulting profits for each division are:

$$
\begin{aligned}
& \pi_{D 1}^{*}=\frac{2}{25}\left(1+c_{o}-2 c_{m}\right)^{2} \\
& \pi_{D 2}^{*}=\frac{1}{25}\left(1+c_{o}-2 c_{m}\right)^{2}
\end{aligned}
$$

The entire company has to pay the total innovation costs $K\left(c_{m}\right)$ and thus has combined profits:

$$
\pi_{I, C D}^{*}=\frac{3}{25}\left(1+c_{o}-2 c_{m}\right)^{2}-K\left(c_{m}\right)
$$

The outsider's profits are:

$$
\pi_{O, C D}^{*}=\frac{1}{25}\left(1-4 c_{o}+3 c_{m}\right)^{2}-K\left(c_{o}\right)
$$

It is easy to see that for identical marginal costs, the overall output rises compared to the benchmark case. This result is a replication of the Creane and Davidson (2005) results that any merger in this setting lowers prices. Furthermore, the profit of the outsider decreases. But without the innovation stage, this merger would also reduce profits of firm 1 and 2 as $3 / 25 \cdot(1-c)^{2}<2 / 16 \cdot(1-c)^{2}$

Maximizing profits with respect to marginal costs yields the first order conditions:

$$
\begin{aligned}
& \frac{\partial \pi_{I, C D}^{*}}{\partial c_{m}}=-\frac{12}{25} \cdot\left(1+c_{o}-2 c_{m}\right)-2 k \cdot\left(c_{m}-c^{0}\right)=0 \\
& \frac{\partial \pi_{O, C D}^{*}}{\partial c_{o}}=-\frac{8}{25} \cdot\left(1-4 c_{o}+3 c_{m}\right)-2 k \cdot\left(c_{o}-c^{0}\right)=0
\end{aligned}
$$

Solving for $c_{m}$ and $c_{o}$ yields: 


$$
\begin{gathered}
c_{m}^{*}=\frac{24-30 k-110 k \cdot c^{0}+125 k^{2} \cdot c^{0}}{24-140 k+125 k^{2}} \\
c_{o}^{*}=\frac{24-20 k-120 k \cdot c^{0}+125 k^{2} \cdot c^{0}}{24-140 k+125 k^{2}}
\end{gathered}
$$

As in case D the optimal investment of the insider is higher than the outsider's optimal investment $\left(c_{m}^{*}<c_{o}^{*}\right)$. The insider's optimal investment is higher than the optimal investment in the benchmark case $\left(c_{m}^{*}<c_{B}^{*}\right)$ while the outsider's investment is lower $\left(c_{o}^{*}>c_{B}^{*}\right)$.

The insider's profit

$$
\pi_{I, C D}^{*}=\frac{3 \cdot\left(-1+c^{0}\right)^{2} \cdot(4-5 k)^{2} \cdot k \cdot(-12+25 k)}{\left(24-140 k+125 k^{2}\right)^{2}}
$$

is larger than two times the benchmark case profit as long as $k<9.20472$. This result is different to the original Creane and Davidson (2005) result. In their setup without innovation a bilateral merger is only profitable if there are at least four firms active in the market. In our setting it is profitable for three active firms in the market, if the innovation costs are not too large.

The outsider's profit

$$
\pi_{O, C D}^{*}=\frac{\left(-1+c^{0}\right)^{2} \cdot(6-5 k)^{2} \cdot k \cdot(-16+25 k)}{\left(24-140 k+125 k^{2}\right)^{2}}
$$

is smaller than in the benchmark case.

Interpretation is quite similar to case $\mathrm{D}$. The insider invests more in $\mathrm{R} \& \mathrm{D}$ and puts pressure on the outsider. This is possible as he can spread his total innovation costs over a larger output. Having less output, the outsider is not able to invest that much in R\&D and therefore has higher marginal costs. Thus, he looses profit compared to the symmetric benchmark case. Total output is

$$
X_{C D}=x_{D 1}^{*}+x_{D 2}^{*}+x_{o}^{*}=\frac{10 \cdot\left(1-c^{0}\right) \cdot k \cdot(-9+10 k)}{24-140 k+125 k^{2}},
$$

which is again larger than in the benchmark case:

$$
\begin{aligned}
3 \cdot x_{B}^{*}-X_{C D} & =3 \cdot \frac{4 \cdot\left(-1+c^{0}\right) \cdot k}{3-16 k}-\frac{10 \cdot\left(1-c^{0}\right) \cdot k \cdot(-9+10 k)}{24-140 k+125 k^{2}} \\
& =\frac{2 \cdot\left(1-c^{0}\right) \cdot k \cdot\left(-9-30 k+50 k^{2}\right)}{-72+804 k-2615 k^{2}+2000 k^{3}}<0
\end{aligned}
$$

In the CD case, the effects from changes in the market structure and innovation of the insider on total output go in the same direction. Without innovation the increase in output would be 
from $3 / 4 \cdot\left(1-c^{0}\right)$ to $4 / 5 \cdot\left(1-c^{0}\right)$. This is due to aggressive behavior of division 1 , the Stackelberg-Leader in the intra firm game. Furthermore, the merged company invests more in innovation compared to the benchmark case and thus marginal costs are reduced more. This leads to an increase in output. The outsider invests less, causing a reduced output but the effect from the changes in market structure and from the merged company overbalance the outsider's reduction und thus, total output increases.

In this setup, consumers always benefit from the merger, for the merging firms it depends on the innovation cost parameter $k$ while the outsider is always harmed by the merger. The effect on social surplus is always positive.

\subsection{Case R\&D Joint Venture}

$R \& D$ joint ventures are often considered to be consumer friendly as wasteful duplication of R\&D efforts is avoided while the output market is still competitive. D'Aspremont and Jacquemin (1988) theoretically analyze the efficiency effects of $R \& D$ joint ventures and Gugler and Siebert (2004) provide empirical evidence for these efficiencies in the semiconductor industry. The main difference between $R \& D$ joint ventures and mergers is that firms remain competitors in the output market.

In our model firm 1 and 2 only cooperate only in the first stage, i.e. in the innovation market. In the second stage, the firms compete on quantities as in the benchmark case. Firm 1 and 2 have an R\&D joint venture leading to identical marginal costs $c_{1}=c_{2}=c_{J V}$. Therefore, the resulting quantities for firm 1 and 2 are also identical. Solving the optimization problem of the second stage yields:

$$
\begin{gathered}
x_{1, J V}^{*}=x_{2, J V}^{*}=\frac{1-2 c_{J V}+c_{3}}{4} \\
x_{3, J V}^{*}=\frac{1+2 c_{J V}-3 c_{3}}{4}
\end{gathered}
$$

The resulting profits, assuming that each firm in the $R \& D$ joint venture pays half of the $R \& D$ costs, are

$$
\begin{gathered}
\pi_{i, J V}^{*}\left(c_{J V}\right)=\left(\frac{1-2 c_{J V}+c_{3}}{4}\right)^{2}-\frac{1}{2} K\left(c_{J V}\right)=x_{i, J V}^{*}\left(c_{J V}\right)^{2}-\frac{1}{2} k\left(c_{J V}-c^{0}\right)^{2} \quad i=1,2 \\
\pi_{3, J V}^{*}\left(c_{3}\right)=\left(\frac{1+2 c_{J V}-3 c_{3}}{4}\right)^{2}-K\left(c_{3}\right)=x_{3, J V}^{*}\left(c_{3}\right)^{2}-k\left(c_{3}-c^{0}\right)^{2} .
\end{gathered}
$$

The combined quantity of firm 1 and 2 is identical to the quantity of the Stackelberg-Leader and the quantity of firm 3 is identical to the one of the follower in case D. This leads to 
identical optimization problems in the first stage as the combined profit of firm 1 and 2 equals the Stackelberg-Leader's profit and the outsider's profit in the joint venture case is also the same as the follower's profit in case D. Thus, investment in innovation, resulting profit, optimal quantities and the other results are identical to case D. The occurrence of identical results in these two cases is of course by chance and is heavily dependent on the assumption of linear demand and constant marginal costs. These assumptions cause the StackelbergLeader in case D to produce exactly two times the quantity of one firm in the benchmark or the $R \& D$ joint venture case. However, in a more general setup we expect the results to be comparable as well. This result is very interesting in the context of merger or R\&D joint ventures approvals. If a certain market structure establishes after the merger, the effects on consumer welfare of a merger is comparable to that of an $R \& D$ joint venture, in our model it is even completely identical. The empirical results of Gugler and Siebert (2004) on market shares at least partly support this view. Both mergers and R\&D joint ventures cause market shares of participating firms to increase, even though the effect is more significant for $R \& D$ joint ventures. ${ }^{13}$

\subsection{Comparative Statics}

In this section we analyze the influence of the model's parameters. By calculating some comparative statics with respect to the initial level of marginal costs and the innovation cost parameter $k$ we derive some interesting results concerning the optimal innovation environment for companies and consumers. Please keep in mind that $k>6 / 5$ is assumed.

The more expensive it is to reduce marginal costs (i.e. the higher $k$ is) the lower is the total quantity supplied, i.e.

$$
\frac{\partial X}{\partial k}<0
$$

in all market structures. This result is not surprising, as the innovation cost parameter influences investments and thus marginal costs. If the reduction of marginal costs gets more expensive, firm's total investment in innovation is decreasing leading to higher marginal costs. ${ }^{14}$ Thus, the overall output decreases. To improve consumer welfare it is therefore always useful to foster an innovation friendly environment.

An interesting result is the change in profits for increasing innovation costs. While the insiders in cases D, CD and JV suffer from increasing innovation costs, the profits of the

\footnotetext{
${ }^{13}$ The superior performance of R\&D joint ventures may be caused by less integration problems of the R\&D department. This is addressed in section 3.

${ }^{14}$ There are exceptions for the outsider's investment in cases D and CD for a certain parameter range (proofs are available from the author upon request). However, the insider's effect is dominant.
} 
outsiders in these cases as well as the profits of firms in the symmetric cases (benchmark and SSR) increase with innovation costs:

$$
\begin{aligned}
& \frac{d \pi_{a}^{*}}{d k}>0 \text { for } a \in\left\{B, S S R, D_{O}, C D_{O}, J V_{I}\right\} \\
& \frac{d \pi_{a}^{*}}{d k}<0 \text { for } a \in\left\{D_{I}, C D_{I}, J V_{I}\right\}
\end{aligned}
$$

The reason for this unexpected result is the effect of $k$ on the innovation market. Of course a decrease of the factor $k$ reduces total innovation costs for a fixed $c$. On the other hand it increases innovation competition. As $k$ increases total investment in innovations is reduced. This leads to higher marginal costs and lower product profitability. But as all firms have higher marginal costs, this loss is not that high. The outsiders and the firms in the symmetric cases overcompensate the loss in product profitability by the reduced investment in innovations. The insiders in cases C, CD and JV have a higher output and therefore the loss in product profitability is higher and cannot be covered by the lower investment in innovations. This result shows that not all firms appreciate reductions in innovation costs. If a government reduces innovation costs, for example by facilitating patent approval processes or by granting innovation support programs, only some firms benefit.

Looking at the profit function of all firms, we see the factor $\left(-1+c^{0}\right)^{2}$ in all cases. Thus, firms’ profits fall with increasing initial marginal costs $c^{0}$ :

$$
\frac{d \pi^{*}}{d c^{0}}<0
$$

In other words, the more efficient firm's initial production is, the higher is the resulting profit.

\section{Decrease of $R \& D$ efficiency due to post merger integration problems}

So far we assumed that the merged firm has the same costs for $R \& D$ as the former independent companies. We relax this assumption to allow for organizational problems. As our focus is the effects on innovation, we only consider inefficiencies of the merging $R \& D$ departments. Cefis et al. (2005) show that firms involved in acquisitions have a lower efficiency in R\&D than independently competing firms. They attribute this efficiency loss to post merger integration problems.

If post merger integration problems occur we assume the R\&D cost function to be 


$$
K\left(c_{i}\right)=\alpha \cdot k \cdot\left(c_{i}-c^{o}\right)^{2}
$$

where $\alpha \in(1 ; 2]$ is an efficiency parameter. Thus, the merged company now faces increased innovation costs $\hat{k}=\alpha \cdot k>k$ compared to the outsider. In this section we analyze the effect of these efficiency losses for each case. ${ }^{15}$ As becomes apparent from the appendix, the resulting complexity of terms does not lend itself to proceed analytically for all parameter values simultaneously. However, the impact of the increased cost of R\&D for merging firms can be visualized by corresponding plots and the study of some representative values for the innovation cost parameter $k$.

\subsection{Case SSR}

The situation is no longer symmetric and so we have to distinguish between insider and outsider. Innovation is now more costly for the merged firm leading to higher marginal cost and lower profits for the insider. The outsider benefits from the increased costs of its rival and invests more in innovation. Thus, the efficiency losses lead to lower profits for the insider and increased profits of the outsider. Figure 1 shows the change of insider's and outsider's profits to the benchmark case for innovation costs between $6 / 5$ and 5 and efficiency parameters $\alpha$ between 1 and 2. We see that for very small $\alpha$ and $k$ the merger is still profitable for the insider. If $\alpha$ or $k$ increases, the merger gets unprofitable. For the outsider, the merger is always profitable. The profitability increases in $\alpha$ as the outsider's superior position in R\&D increases with $\alpha$. The occurrence of integration problems worsens the situation for consumers. The merger leads to a decrease in total output. With increasing integration problems, total innovation costs rise leading to higher marginal costs and a lower output of each firm. The same is true for social surplus. Only for very small innovation costs and little integration problems the merger can enhance social surplus.

\footnotetext{
${ }^{15}$ Calculations are basically the same as before and are given in the appendix. The innovation decision in the joint venture case is still identical to case D.
} 

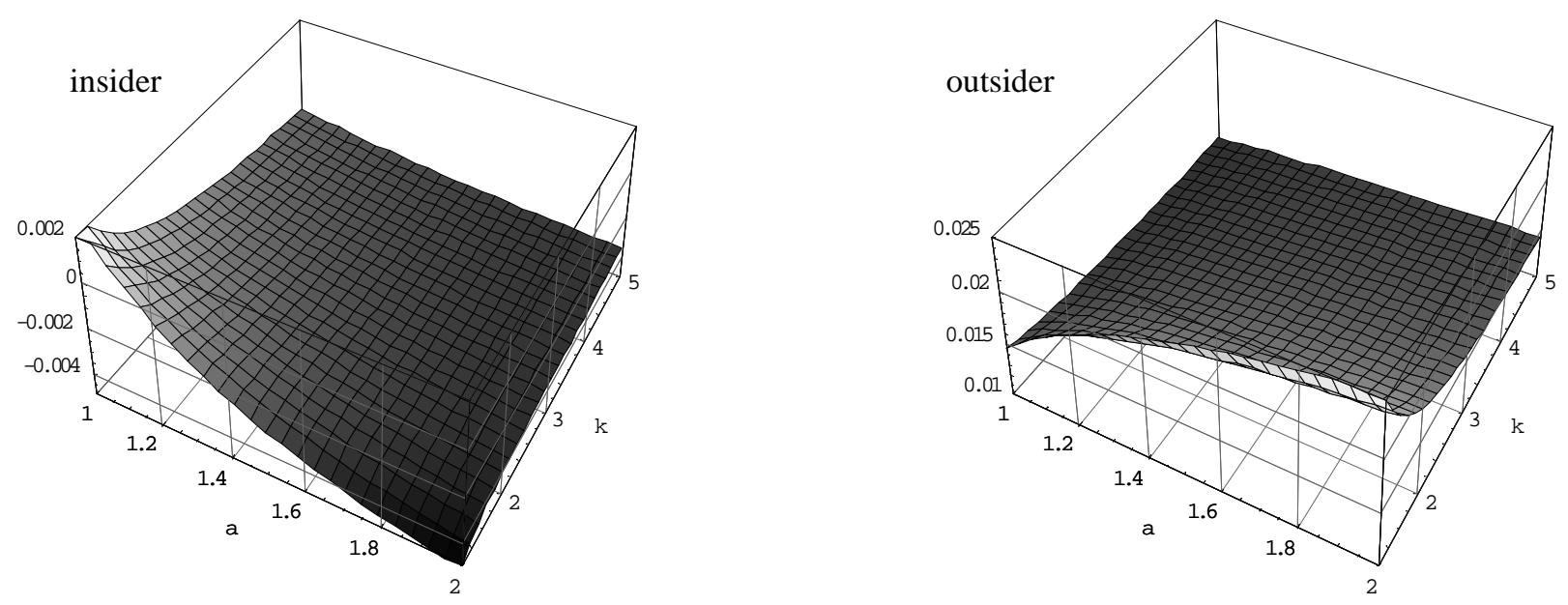

Figure 1: Profit comparison case SSR, insider and outsider

\subsection{Case D}

If integration problems occur, the position of the Stackelberg leader is not as dominant as before. The merged company now has increased costs of innovation compared to the outsider while it can still spread these costs over a larger output. The dominating effect is dependent on $\alpha$. For $\alpha<4 / 3$ the size effect dominates and the insider still invests more in innovation compared to the benchmark case. The outsider invests more if the effect from increased costs dominates, i.e. if $\alpha>4 / 3$. For $\alpha=4 / 3$ both the insider and outsider have the same marginal costs as in the benchmark case. As the Stackelberg-Leader produces exactly twice the quantity of one firm and the follower the same as one firm in a Cournot Triopoly, total output is then also identical to the benchmark case. Figure 2 shows a comparison of total quantity before and after the merger.

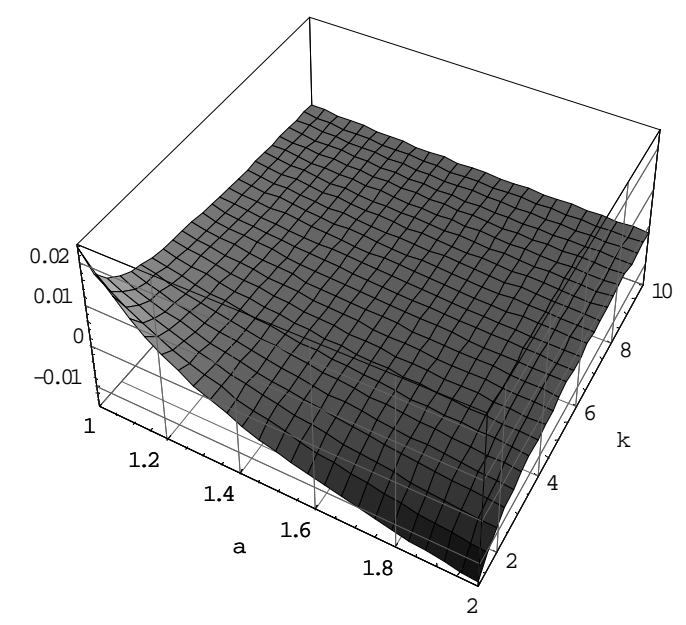

Figure 2: Changes in total quantity, case D

We see that consumers benefit from the merger if $\alpha<4 / 3$, i.e. if the larger firm has lower marginal costs. The profit of the insider is increasing except for high $\alpha$ and small $k$ (see 
figure 3). If $\alpha$ is high he does not benefit much from its reduction of R\&D departments and if $\mathrm{k}$ is small, the outsider reduces marginal costs very much causing a loss of market share for the insider. The outsider benefits from the merger if $\alpha>4 / 3$. Social surplus is always increasing.
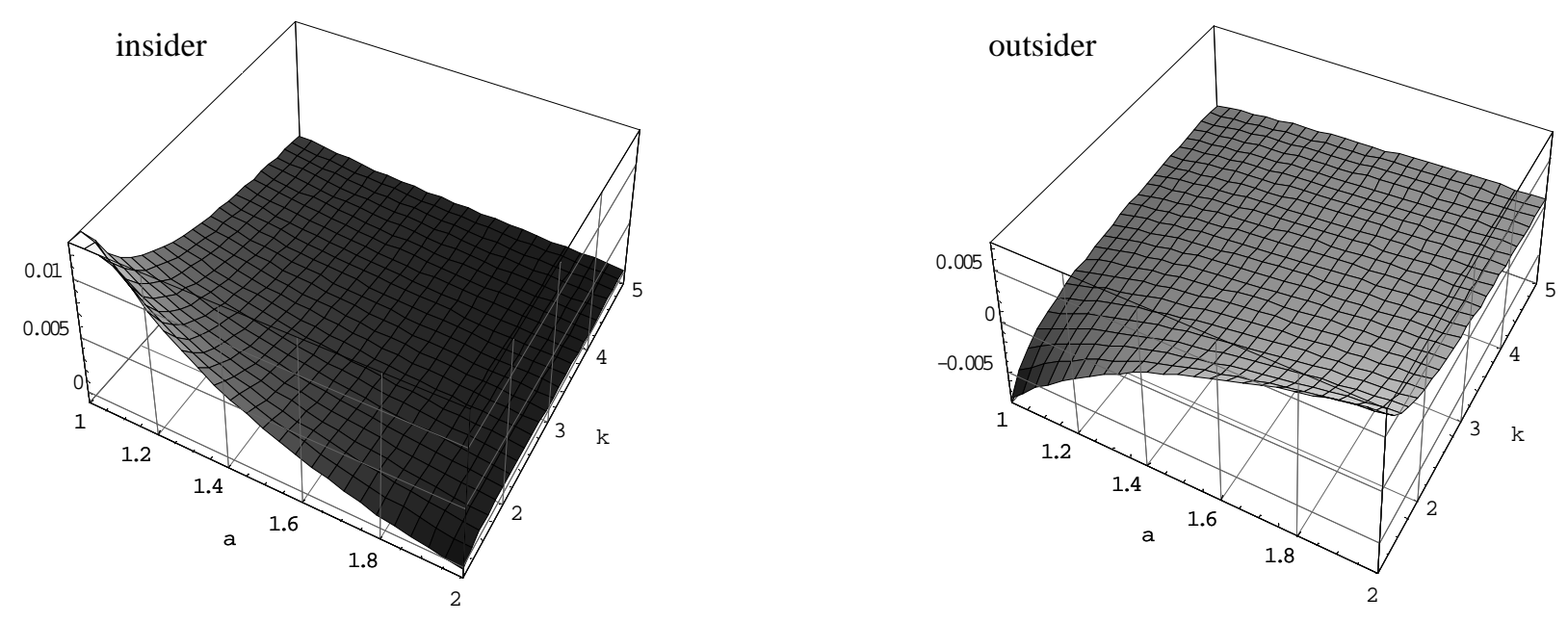

Figure 3: Profit comparison case D, insider and outsider

\subsection{Case CD}

In the CD case, the insider invests more compared to the benchmark case up to a certain limit of $\alpha$ which depends on $k$. The outsider invests less, except for really low values of $k$ and high values of $\alpha$. The merger is profitable for the insider if integration problems are not too high and is never beneficial for the outsider (see figure 4).
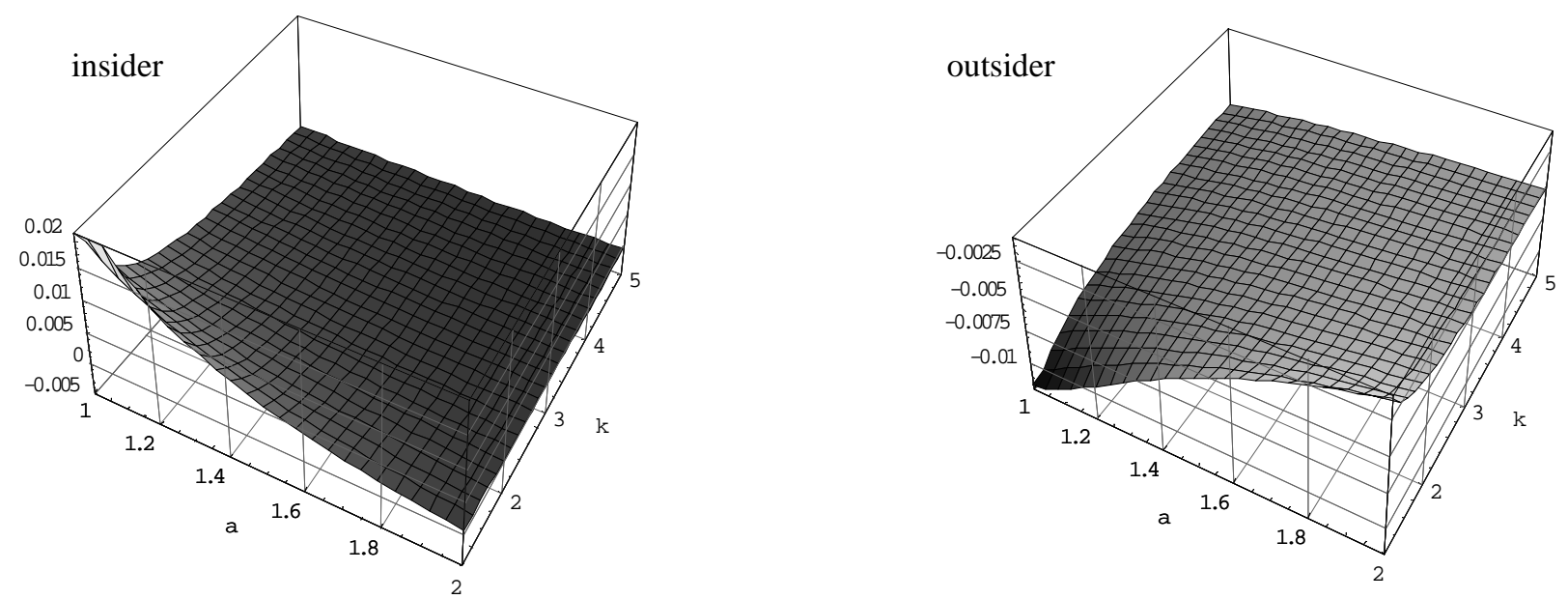

Figure 4: Profit comparison case CD, insider and outsider

Total quantity and social surplus are always increased. This is due to the changed organization in the merged company. The aggressive behavior of the intrafirm Stackelberg-Leader causes total quantity to rise significantly and thus leading to higher consumer surplus. If integration problems and innovation costs are very high it is possible that both firms loose profit due to 
the merger. Even in this situation the rise in consumer surplus caused by the changed market structure overcompensates this loss leading to an increase in social surplus.

\subsection{Summary}

To illustrate results, we analyze the changes compared to the benchmark case for some exemplary innovation cost parameters in table 1.

\begin{tabular}{|c|c|c|c|c|c|c|}
\hline & $\begin{array}{l}\text { Investment } \\
\text { Insider }\end{array}$ & $\begin{array}{l}\text { Investment } \\
\text { Outsider }\end{array}$ & $\begin{array}{l}\text { Profits } \\
\text { Insider }\end{array}$ & $\begin{array}{c}\text { Profits } \\
\text { Outsider }\end{array}$ & $\begin{array}{c}\text { Total } \\
\text { Quantity }\end{array}$ & $\begin{array}{c}\text { Social } \\
\text { Surplus }\end{array}$ \\
\hline $\begin{array}{l}\text { SSR } \\
\mathrm{k}=6 / 5\end{array}$ & $\begin{array}{c}\nearrow \\
\text { if } \alpha<1.13\end{array}$ & $\nearrow$ & $\begin{array}{c}\nearrow \\
\text { if } \alpha<1.17\end{array}$ & $\nearrow$ & $\searrow$ & $\begin{array}{c}\nearrow \\
\text { if } \alpha<1.29\end{array}$ \\
\hline $\begin{array}{l}\mathrm{SSR} \\
\mathrm{k}=3 / 2\end{array}$ & $\begin{array}{c}\nearrow \\
\text { if } \alpha<1.15\end{array}$ & $\nearrow$ & $\begin{array}{c}\nearrow \\
\text { if } \alpha<1.11\end{array}$ & $\nearrow$ & $\searrow$ & $\begin{array}{c}\nearrow \\
\text { if } \alpha<1.03\end{array}$ \\
\hline $\begin{array}{l}\text { SSR } \\
\mathrm{k}=5\end{array}$ & $\begin{array}{c}\nearrow \\
\text { if } \alpha<1.18\end{array}$ & $\nearrow$ & $\searrow$ & $\nearrow$ & $\searrow$ & $\searrow$ \\
\hline $\begin{array}{l}\mathrm{D} / \mathrm{JV} \\
\mathrm{k}=6 / 5\end{array}$ & $\begin{array}{c}\nearrow \\
\text { if } \alpha<1.33\end{array}$ & $\begin{array}{c}\searrow \\
\text { if } \alpha<1.33\end{array}$ & $\begin{array}{c}\nearrow \\
\text { if } \alpha<1.96\end{array}$ & $\begin{array}{c}\searrow \\
\text { if } \alpha<1.33\end{array}$ & $\begin{array}{c}\nearrow \\
\text { if } \alpha<1.33\end{array}$ & $\nearrow$ \\
\hline $\begin{array}{l}\mathrm{D} / \mathrm{JV} \\
\mathrm{k}=3 / 2\end{array}$ & $\begin{array}{c}\nearrow \\
\text { if } \alpha<1.33\end{array}$ & $\begin{array}{c}\searrow \\
\text { if } \alpha<1.33\end{array}$ & $\nearrow$ & $\begin{array}{c}\searrow \\
\text { if } \alpha<1.33\end{array}$ & $\begin{array}{c}\nearrow \\
\text { if } \alpha<1.33\end{array}$ & $\nearrow$ \\
\hline $\begin{array}{l}\mathrm{D} / \mathrm{JV} \\
\mathrm{k}=5\end{array}$ & $\begin{array}{c}\nearrow \\
\text { if } \alpha<1.33\end{array}$ & $\begin{array}{c}\searrow \\
\text { if } \alpha<1.33\end{array}$ & $\nearrow$ & $\begin{array}{c}\searrow \\
\text { if } \alpha<1.33\end{array}$ & $\begin{array}{c}\nearrow \\
\text { if } \alpha<1.33\end{array}$ & $\nearrow$ \\
\hline $\mathrm{CD} \mathrm{k}=6 / 5$ & $\begin{array}{c}\nearrow \\
\text { if } \alpha<1.34\end{array}$ & $\begin{array}{c}\searrow \\
\text { if } \alpha<1.79\end{array}$ & $\nearrow$ & $\searrow$ & $\nearrow$ & $\nearrow$ \\
\hline $\mathrm{CD} \mathrm{k}=3 / 2$ & $\begin{array}{c}\nearrow \\
\text { if } \alpha<1.32\end{array}$ & $\searrow$ & $\nearrow$ & $\searrow$ & $\nearrow$ & $\nearrow$ \\
\hline $\mathrm{CD} \mathrm{k}=5$ & $\begin{array}{c}\nearrow \\
\text { if } \alpha<1.29\end{array}$ & $\searrow$ & $\begin{array}{c}\nearrow \\
\text { if } \alpha<1.52\end{array}$ & $\searrow$ & $\nearrow$ & $\nearrow$ \\
\hline
\end{tabular}

Table 1 Comparisons for illustrative innovation cost parameters

If we allow for efficiency losses of the R\&D department we get ambiguous results caused by the effect of innovation costs. In the SSR case the insider is even worse off. Without integration problems he was at least in an identical situation as the outsider, now he suffers from less efficient innovation. The merged firm in cases D and CD can spread its total innovation costs over a larger output but innovation costs increase due to the losses in $R \& D$ efficiency. The positive effects on market shares for the insider are reduced because of the integration problems. Still insiders tend to benefit from mergers in case D and CD but only up to a certain bound $\alpha(k)$. The outsider is always harmed by the merger in case CD, in case $\mathrm{D}$ only up to $\alpha=4 / 3$. In all cases the outsider benefits from an increase in $\alpha$ as this improves his position in the innovation market. The introduction of integration problems also leads to changes in welfare analysis. Less efficient R\&D harms consumers as marginal costs after innovation are higher and thus total quantity is lower. In case D a merger without integration 
problems is always beneficial for consumers while sufficiently large integration problems lead to a decrease in consumer surplus.

This result may partly explain the empirical findings of Gugler and Siebert (2004). If we expect the integration problems of R\&D joint ventures to be lower than those of mergers, for example because the integration can fully concentrate on R\&D issues, the $\alpha$ of $R \& D$ joint ventures would be lower compared to mergers. Thus, innovation is more efficiently performed in the joint venture leading to a more significant increase in market shares for firms participating in R\&D joint ventures compared to merging firms.

\section{Conclusion}

This paper shows - in a simplified framework - the effects of a merger on the incentives to innovate in different market structures. In our 3 firm model we allow firms to invest in innovation in the first stage and to set optimal quantities in the second. Thus, firms first compete on the innovation market and strategically set their investment in innovation that determines their marginal costs of production. Then they compete in quantities. We compare the basic situation with three identical firms to merger and R\&D joint venture situations. In all resulting market structures, a merger can be beneficial to the merging company, depending on the innovation cost parameter $k$. In the SSR and CD case it is only beneficial if innovation costs are sufficiently low while in case $D$ (and for an $R \& D$ joint venture) it is beneficial independent of the innovation costs. Except for the SSR case, where insider and outsider are symmetric, the outsider is harmed by the merger. This result is in accordance with empirical results from Banerjee and Eckard (1998) analyzing the first great merger wave. In all asymmetric cases the merger is disadvantageous for the outsider. A characteristic result of all asymmetric situations is that the insider invests more in innovation compared to the benchmark case while the outsider invests less. The reason for this result is that the insider can spread his total innovation costs over more output and therefore has higher incentives to reduce his marginal costs. Consumers benefit from the merger (except for the SSR case). The asymmetrical situation leads to higher investments in innovation, lower marginal cost and therefore to a better supply of the good.

If we allow for decreasing R\&D efficiency due to the merger results get ambiguous. The effect from increased innovation costs pushes in the opposite direction as the effect caused by increased output. Thus, results depend heavily on the changes in R\&D efficiency. 
Our model has several limitations. Firstly, we do not consider uncertainty about the results of R\&D effort. While this is certainly a key aspect of innovation, we omit the problem of unknown outcomes of $R \& D$ investments and the associated discussion about the degree of risk aversion to have a clear focus on the innovation incentives resulting from changes in market structure. Secondly, our model is static. We do not consider entry of new competitors in the market that occurs despite of large fixed costs in high technology and R\&D intensive markets or follow-up investments in innovation. Hence, an important extension to our model would be a dynamic way of modeling innovation and allowing for entry. Furthermore, we do not consider the possibility to license the improved technology to competitors. As the approval processes of mergers often discuss remedies like mandatory licensing to outsiders, including the possibility to license innovation would be an extension that makes our model more realistic. However, this would completely change the competition for innovation in our model as these process innovations are then most efficiently performed by only one company and effectively a 3 firm R\&D joint venture without innovation competition is created. A third simplification of our model is our assumption about the cost structure of innovation and the linear demand for the homogeneous good. We think that our findings do not change qualitatively with more general demand structures and R\&D cost functions, although some specific results, like the identical outcomes for cases $D$ and $R \& D$ joint ventures would be altered of course. However, these assumptions simplify notation and analysis, especially the calculations of sub-game perfect equilibria. The preponderance of results concerning the surplus enhancing effect of mergers in an innovation context needs an analysis of more general demand and cost structures.

Further research in this field should concentrate on the effect of relatedness of firms on changes in R\&D efficiency. The analysis of Cassiman et al. (2005) shows that technology and market relatedness of firms has a significant impact on post-merger R\&D efficiency. In a model with heterogeneous firms the merger decision could then be endogenised to explain horizontal mergers. 


\section{References}

BANAL-ESTANOL, A., MACHO-STADLER, I. and J. SELDESLACHTS, (2004): Mergers, investment decisions and internal organisation, Wissenschaftszentrum Berlin, Discussion Paper, SP II 2004-13

BANERJEE, A. and E. W. ECKARD (1998): Are mega-mergers anticompetitive? Evidence from the first great merger wave, Rand Journal of Economics, 29, pp.803 - 827

BOMMER, M. and D. S. JALAJAS. (1999): The threat of organizational downsizing on the innovative propensity of R\&D professionals, $R \& D$ Management, 29, pp. 27 - 34

CASSIMAN, B., COLOMBO, M. G., GARRONE, P. and R. VEUGELERS, (2005): The impact of M\&A on the R\&D process: An empirical analysis of the role of technological- and market-relatedness, Research Policy, 34, pp. 195 - 220

CEFIS, E., ROSENKRANZ, S. and U. WEITZEL (2005): Effects of acquisitions on product and process innovation and R\&D performance, CEPR Discussion Paper, No. 5275

COHEN, W.M. and LEVINTHAL, D.A. (1989): Innovation and learning: The two faces of R\&D, Economic Journal, 99, pp. 569 - 596

CREANE, A. and C. DAVIDSON (2005): Multidivisional firms, staggered competition and the merger paradox, Canadian Journal of Economics, 37,pp 951 - 977

D’ASPREMONT, C. and A. JACQUEMIN (1988): Cooperative and noncooperative R\&D in duopoly with spillovers, American Economic Review, 78, pp. 1133 - 1137.

DAUGHETY, A. F. (1990): Beneficial concentration, American Economic Review, 80, pp. $1231-1237$

DESSYLLAS, P. and A. HUGHES (2005): R\&D and patenting activity and the propensity to acquire in high technology industries, ESCR Working Paper, No. 298 
ERNST, H. and J. VITT (2000): The influence of corporate acquisitions on the behaviour of key inventors, R\&D Management, 30, p.105 - 119

FARRELL, J. and C. Shapiro (1990): Horizontal Mergers: An Equilibrium Analysis, American Economic Review, Vol. 80, No. 1, pp. 107-126

GILBERT, R. and W. K. Tom (2001): Is innovation king at the antitrust agencies? The intellectual property guidelines five years later, Antitrust law journal, 69, pp. 43 - 86

GUGLER, K. and R. SIEBERT (2004): Market power versus efficiency effects of mergers and research joint ventures: Evidence from the semiconductor industry, NBER Working Paper, No. 10323

HAGEDOORN, J. and G. DUYSTERS, (2000): The effect of mergers and acquisitions on the technological performance of companies in a high-tech environment, working paper, download from http://www.merit.unimaas.nl/

HUCK, S., KONRAD, K. A. and W. MÜLLER (2004): Profitable horizontal mergers without cost advantages: The role of internal organization, information and market structure, Economica, 71, pp. 575 - 587

JOST, P. J. and C. VAN DER VELDEN (2006): Mergers in patent contest models with synergies and spillovers, Schmalenbach Business Review, 58, pp. 157 - 179

KATZ, M.L. and H. A. SHELANSKI (2004): Merger policy and innovation: Must enforcement change to account for technological change?, NBER Working Paper, No. 10710

KATZ, R. and ALLEN, T. J. (1982): Investigating the not-invented-here (NIH) syndrome: A look at the performance, tenure and communications patterns of $50 \mathrm{R} \& \mathrm{D}$ project groups, $R \& D$ Management, 12, pp. 7 - 19

RÖLLER, L-H., STENNEK, J. and F. VERBOVEN (2000): Efficiency gains from mergers, Wissenschaftszentrum Berlin, Discussion Paper, FS IV 00-09 
ROSENKRANZ, S. (2003): Simultaneous choice of process and product innovation when consumers have a preference for product variety, Journal of Economic Behavior \& Organization, 50, pp. 183 - 201

SALANT, S. W., SWITZER, S. and R. J. REYNOLDS (1983): Losses from horizontal merger: The effects of an exogenous change in industry structure on Cournot-Nash equilibrium, Quarterly Journal of Economics, 98, pp. 185 - 199

VIVES, X. (2004): Innovation and competitive pressure, CEPR Discussion Paper, No. 4369 


\section{Appendix}

\section{Lower bound for innovation cost parameter $k$ :}

If innovation costs are too low, the insider can reduce its marginal costs that much that the outsider is forced to leave the market. The power of the insider is dependent on its market share and is greatest in case CD.

We solve for the innovation costs where the optimal marginal costs of the outsider is identical to the initial marginal costs, i.e. the costs where the outsider does not innovate at all.

$$
\begin{aligned}
c_{o}^{*}=\frac{24-20 k-120 k \cdot c^{0}+125 k^{2} \cdot c^{0}}{24-140 k+125 k^{2}} & \stackrel{!}{=} c^{0} \\
\Leftrightarrow 24-20 k-120 k \cdot c^{0}+125 k^{2} \cdot c^{0} & =c^{0} \cdot\left(24-140 k+125 k^{2}\right) \\
\Leftrightarrow k & =6 / 5
\end{aligned}
$$

If $k>6 / 5$, the outsider cannot be pushed out of the innovation market.

\section{Second order conditions for the innovation stage:}

To assure concavity of the profit function, the innovation cost parameter $k$ must satisfy the following conditions.

\section{Benchmark}

$$
\begin{gathered}
\frac{\partial \pi_{i, B}^{*}}{\partial c_{i}}=-\frac{6}{16} \cdot\left(1-3 c_{i}+c_{j}+c_{k}\right)-2 k \cdot\left(c_{i}-c^{0}\right) \\
\Rightarrow \frac{\partial^{2} \pi_{i, B}^{*}}{\partial c_{i}^{2}}=\frac{9}{8}-2 k<0 \\
\Leftrightarrow k>9 / 16
\end{gathered}
$$

SSR

$$
\begin{gathered}
\frac{\partial \pi_{i, S S R}^{*}}{\partial c_{i}}=-\frac{4}{9}\left(1-2 c_{i}+c_{j}\right)-2 k \cdot\left(c_{i}-c^{0}\right) \\
\Rightarrow \frac{\partial^{2} \pi_{i, S S R}^{*}}{\partial c_{i}^{2}}=\frac{8}{9}-2 k \stackrel{!}{<0} \\
\Leftrightarrow k>4 / 9
\end{gathered}
$$

D (JV)

$$
\begin{gathered}
\frac{\partial \pi_{I, D}^{*}}{\partial c_{M}}=-\frac{1}{2}\left(1-2 c_{M}+c_{O}\right)-2 k \cdot\left(c_{M}-c^{0}\right) \\
\Rightarrow \frac{\partial^{2} \pi_{I, D}^{*}}{\partial c_{M}{ }^{2}}=1-2 k<0 \\
\Leftrightarrow k>1 / 2
\end{gathered}
$$




$$
\begin{gathered}
\frac{\partial \pi_{O, D}^{*}}{\partial c_{O}}=-\frac{3}{8}\left(1+2 c_{M}-3 c_{O}\right)-2 k \cdot\left(c_{O}-c^{0}\right) \\
\Rightarrow \frac{\partial^{2} \pi_{I, D}^{*}}{\partial c_{M}{ }^{2}}=\frac{9}{8}-2 k \stackrel{!}{<0} \\
\Leftrightarrow k>9 / 16
\end{gathered}
$$

CD

$$
\begin{aligned}
& \frac{\partial \pi_{I, C D}^{*}}{\partial c_{m}}=-\frac{12}{25} \cdot\left(1+c_{o}-2 c_{m}\right)-2 k \cdot\left(c_{m}-c^{0}\right) \\
& \Rightarrow \frac{\partial^{2} \pi_{I, C D}^{*}}{\partial c_{m}{ }^{2}}=\frac{24}{25}-2 k \dot{<} 0 \\
& \Leftrightarrow k>12 / 25 \\
& \frac{\partial \pi_{O, C D}^{*}}{\partial c_{o}}=-\frac{8}{25} \cdot\left(1-4 c_{o}+3 c_{m}\right)-2 k \cdot\left(c_{o}-c^{0}\right) \\
& \Rightarrow \frac{\partial^{2} \pi_{O, C D}^{*}}{\partial c_{o}{ }^{2}}=\frac{32}{25}-2 k<0 \\
& \Leftrightarrow k>16 / 25
\end{aligned}
$$

In all cases, the second order conditions are satisfied as $k>6 / 5$ is assumed.

\section{Lower bound for initial costs:}

To assure nonnegative marginal costs, it is necessary that the initial costs $c^{0}$ are higher than a certain bound.

\section{Benchmark}

$$
\begin{aligned}
c_{i, B}^{*}=\frac{16 k \cdot c^{0}-3}{16 k-3} & \geq 0 \\
\Leftrightarrow c^{0} & \geq \frac{3}{16 k}
\end{aligned}
$$

SSR

$$
\begin{aligned}
c_{i, S S R}^{*}=\frac{9 k \cdot c^{0}-2}{9 k-2} & \geq 0 \\
\Leftrightarrow c^{0} & \geq \frac{2}{9 k}
\end{aligned}
$$




\section{D (JV)}

$$
\begin{aligned}
c_{M}^{*}=\frac{3-4 k-13 k \cdot c^{0}+16 k^{2} \cdot c^{0}}{3-17 k+16 k^{2}} & \geq 0 \\
\Leftrightarrow c^{0} & \geq \frac{4 k-3}{16 k^{2}-13 k} \quad(a) \\
c_{O}^{*}=\frac{3-3 k-14 k \cdot c^{0}+16 k^{2} \cdot c^{0}}{3-17 k+16 k^{2}} & \geq 0 \\
\Leftrightarrow c^{0} & \geq \frac{3 k-3}{16 k^{2}-14 k}
\end{aligned}
$$

CD

$$
\begin{aligned}
c_{m}^{*}=\frac{24-30 k-110 k \cdot c^{0}+125 k^{2} \cdot c^{0}}{24-140 k+125 k^{2}} & \geq 0 \\
\Leftrightarrow c^{0} & \geq \frac{30 k-24}{125 k^{2}-110 k} \\
c_{o}^{*}=\frac{24-20 k-120 k \cdot c^{0}+125 k^{2} \cdot c^{0}}{24-140 k+125 k^{2}} & \geq 0 \\
\Leftrightarrow c^{0} & \geq \frac{20 k-24}{125 k^{2}-120 k}
\end{aligned}
$$

The critical bounds are $(a)$ and $(b)$, leading to the following condition for initial marginal costs:

$$
c^{0} \geq \max \left\{\frac{4 k-3}{16 k^{2}-13 k} ; \frac{30 k-24}{125 k^{2}-110 k}\right\}
$$

Bound $(a)$ is critical for $k>1.4131$, bound $(b)$ for $k<1.4131 .^{16}$

\section{Profit comparisons:}

\section{Benchmark vs. SSR}

Comparing the combined profit of two firms in the benchmark case with the insider's profits in case SSR yields:

$$
\begin{aligned}
2 \cdot \pi_{B}^{*}-\pi_{S S R}^{*} & =2 \cdot \frac{k \cdot\left(1-c^{0}\right)^{2} \cdot(-9+16 k)}{(3-16 k)^{2}}-\frac{\left(c^{0}-1\right)^{2} \cdot k \cdot(-4+9 k)}{(2-9 k)^{2}} \\
& =\left(1-c^{0}\right)^{2} \cdot k \cdot \frac{\left(-36+311 k-722 k^{2}+288 k^{3}\right)}{\left(6-59 k+144 k^{2}\right)^{2}}
\end{aligned}
$$

The denominator is positive for all admissible values of $k$. The sign of the numerator depends on the term $-36+311 k-722 k^{2}+288 k^{3}$ which is negative for $k \in[6 / 5,1.9977)$ and positive

\footnotetext{
${ }^{16}$ For $k=6 / 5$ we have the highest lower barrier $c^{0} \geq 0.25$.
} 
for $k \in(1.9977 ; \infty)$. Thus the merger is profitable for the merging firms if $k$ is below that bound.

The outsider's profit is always larger than the profit of a single firm in the benchmark case as

$$
\begin{aligned}
\pi_{B}^{*}-\pi_{S S R}^{*} & =\frac{k \cdot\left(1-c^{0}\right)^{2} \cdot(-9+16 k)}{(3-16 k)^{2}}-\frac{\left(c^{0}-1\right)^{2} \cdot k \cdot(-4+9 k)}{(2-9 k)^{2}} \\
& =-\left(1-c^{0}\right)^{2} \cdot k^{2} \cdot \frac{\left(77-583 k+1008 k^{2}\right)}{\left(6-59 k+144 k^{2}\right)^{2}}<0 .
\end{aligned}
$$

\section{Benchmark vs. D (respectively JV)}

The combined profit of two firms in the benchmark case is always smaller than the insider's profit in case D:

$$
\begin{aligned}
2 \cdot \pi_{B}^{*}-\pi_{I, D}^{*} & =2 \cdot \frac{k \cdot\left(1-c^{0}\right)^{2} \cdot(-9+16 k)}{(3-16 k)^{2}}-\frac{\left(-1+c^{0}\right)^{2}(3-4 k)^{2} \cdot k \cdot(-1+2 k)}{\left(3-17 k+16 k^{2}\right)^{2}} \\
& =-\left(-1+c^{0}\right)^{2} \cdot k \cdot \frac{\left(81-882 k+3282 k-4928 k^{3}+2560 k^{4}\right)}{\left(9-99 k+320 k^{2}-256 k^{3}\right)^{2}}<0
\end{aligned}
$$

The benchmark case profit of one firm is always higher than the outsider's profit:

$$
\begin{aligned}
\pi_{B}^{*}-\pi_{O, D}^{*} & =\frac{k \cdot\left(1-c^{0}\right)^{2} \cdot(-9+16 k)}{(3-16 k)^{2}}-\frac{\left(-1+c^{0}\right)^{2}(-1+k)^{2} \cdot k \cdot(-9+16 k)}{\left(3-17 k+16 k^{2}\right)^{2}} \\
& =4 \cdot\left(-1+c^{0}\right)^{2} \cdot k^{2} \cdot \frac{\left(-27+210 k-432 k^{2}+256 k^{3}\right)}{\left(9-99 k+320 k^{2}-256 k^{3}\right)^{2}}>0
\end{aligned}
$$

\section{Benchmark vs. CD}

Comparing the combined profit of two firms in the benchmark case with the insider's profits in case CD yields:

$$
\begin{aligned}
2 \cdot \pi_{B}^{*}-\pi_{I, C D}^{*} & =2 \cdot \frac{k \cdot\left(1-c^{0}\right)^{2} \cdot(-9+16 k)}{(3-16 k)^{2}}-\frac{3 \cdot\left(-1+c^{0}\right)^{2} \cdot(4-5 k)^{2} \cdot k \cdot(-12+25 k)}{\left(24-140 k+125 k^{2}\right)^{2}} \\
& =\left(1-c^{0}\right)^{2} \cdot k \cdot \frac{\left(-5184+60336 k-239844 k^{2}+382085 k^{3}-222850 k^{4}+20000 k^{5}\right)}{\left(72-804 k+2615 k^{2}-2000 k^{3}\right)^{2}}
\end{aligned}
$$

The sign of this expression depends on the sign of the numerator which is negative for $k<9.20472$ and positive for $k>9.20472$. Thus, a merger in case CD is profitable if $k$ is below that bound.

The benchmark case profit of one firm is always higher than the outsider's profit: 


$$
\begin{aligned}
\pi_{B}^{*}-\pi_{O, C D}^{*} & =\frac{k \cdot\left(1-c^{0}\right)^{2} \cdot(-9+16 k)}{(3-16 k)^{2}}-\frac{\left(-1+c^{0}\right)^{2} \cdot(6-5 k)^{2} \cdot k \cdot(-16+25 k)}{\left(24-140 k+125 k^{2}\right)^{2}} \\
& =4 \cdot\left(-1+c^{0}\right)^{2} \cdot k^{2} \cdot \frac{\left(-2340+5196 k+60415 k^{2}-154225 k^{3}+90000 k^{4}\right)}{\left(72-804 k+2615 k^{2}-2000 k^{3}\right)^{2}}>0
\end{aligned}
$$

\section{Investment comparisons:}

\section{Benchmark vs. SSR}

The optimal marginal costs in case SSR are lower than in the benchmark case:

$$
c_{i, S S R}^{*}-c_{i, B}^{*}=\frac{9 k \cdot c^{0}-2}{9 k-2}-\frac{16 k \cdot c^{0}-3}{16 k-3}=-\frac{5 \cdot\left(1-c^{0}\right) \cdot k}{6-59 k+144 k^{2}}<0
$$

\section{Benchmark vs. D (respectively JV)}

The Stackelberg-Leader invests more in cost reducing innovations than the firms in the benchmark case which invest more than the followers $\left(c_{M}^{*}<c_{B}^{*}<c_{O}^{*}\right)$ :

$$
\begin{aligned}
& c_{M}^{*}-c_{B}^{*}=\frac{3-4 k-13 k \cdot c^{0}+16 k^{2} \cdot c^{0}}{3-17 k+16 k^{2}}-\frac{16 k \cdot c^{0}-3}{16 k-3}=\frac{\left(-1+c^{0}\right) \cdot k \cdot(-9+16 k)}{-9+99 k-320 k^{2}+256 k^{3}}<0 \\
& c_{O}^{*}-c_{B}^{*}=\frac{3-3 k-14 k \cdot c^{0}+16 k^{2} \cdot c^{0}}{3-17 k+16 k^{2}}-\frac{16 k \cdot c^{0}-3}{16 k-3}=-\frac{6 \cdot\left(-1+c^{0}\right) \cdot k}{-9+99 k-320 k^{2}+256 k^{3}}>0 \\
& \Rightarrow c_{M}^{*}<c_{B}^{*}<c_{O}^{*}
\end{aligned}
$$

\section{Benchmark vs. CD}

The insider's investment in cost reducing innovations is higher than the one of a firm in the benchmark case which is again higher than the investment of the outsider $\left(c_{m}^{*}<c_{B}^{*}<c_{o}^{*}\right)$ :

$$
\begin{aligned}
& c_{m}^{*}-c_{B}^{*}=\frac{24-30 k-110 k \cdot c^{0}+125 k^{2} \cdot c^{0}}{24-140 k+125 k^{2}}-\frac{16 k \cdot c^{0}-3}{16 k-3} \\
&=\frac{3 \cdot\left(c^{0}-1\right) \cdot k \cdot(-18+35 k)}{-72+804 k-2615 k^{2}+2000 k^{3}}<0 \\
& c_{o}^{*}-c_{B}^{*}=\frac{24-20 k-120 k \cdot c^{0}+125 k^{2} \cdot c^{0}}{24-140 k+125 k^{2}}-\frac{16 k \cdot c^{0}-3}{16 k-3} \\
&=-\frac{\left(c^{0}-1\right) \cdot k \cdot(24+55 k)}{-72+804 k-2615 k^{2}+2000 k}>0 \\
& \Rightarrow c_{m}^{*}<c_{B}^{*}<c_{o}^{*}
\end{aligned}
$$




\section{Social surplus:}

Social surplus $W$ is given by the sum of the firm's profit plus consumer surplus, which is half the total quantity squared in our case of linear demand.

\section{Benchmark}

$$
W_{B}=3 \cdot \frac{k \cdot\left(1-c^{0}\right)^{2} \cdot(-9+16 k)}{(3-16 k)^{2}}+\frac{1}{2}\left(3 \cdot \frac{4 \cdot\left(1-c^{0}\right) \cdot k}{16 k-3}\right)^{2}=\frac{\left(1-c^{0}\right)^{2} \cdot k \cdot(-9+40 k)}{(3-16 k)^{2}}
$$

SSR

$$
\begin{aligned}
& W_{S S R}=2 \cdot \frac{\left(1-c^{0}\right)^{2} \cdot k \cdot(-4+9 k)}{(2-9 k)^{2}}+\frac{1}{2}\left(2 \cdot \frac{3 \cdot\left(1-c^{0}\right) \cdot k}{9 k-2}\right)^{2}=\frac{4 \cdot\left(1-c^{0}\right)^{2} \cdot k}{-2+9 k} \\
& W_{B}-W_{S S R}=\frac{\left(1-c^{0}\right)^{2} \cdot k \cdot\left(18-99 k+56 k^{2}\right)}{(3-16 k)^{2} \cdot(-2+9 k)}
\end{aligned}
$$

Social surplus is thus larger in the benchmark case if $18-99 k+56 k^{2}>0$ which is true for $k>1.56209$.

\section{D (JV)}

$$
\begin{aligned}
& W_{D}=\frac{\left(-1+c^{0}\right)^{2}(3-4 k)^{2} \cdot k \cdot(-1+2 k)}{\left(3-17 k+16 k^{2}\right)^{2}}+\frac{\left(-1+c^{0}\right)^{2}(-1+k)^{2} \cdot k \cdot(-9+16 k)}{\left(3-17 k+16 k^{2}\right)^{2}} \\
&+\frac{1}{2} \cdot\left(\frac{2 \cdot\left(1-c^{0}\right) \cdot k \cdot(-5+6 k)}{3-17 k+16 k^{2}}\right)^{2}=\frac{3 \cdot\left(1-c^{0}\right)^{2} \cdot k \cdot\left(-6+42 k-75 k^{2}+40 k^{3}\right)}{\left(3-17 k+16 k^{2}\right)^{2}} \\
& W_{B}-W_{D}=-\frac{3 \cdot\left(1-c^{0}\right)^{2} \cdot k \cdot\left(27-324 k+1302 k^{2}-1984 k^{3}+1024 k^{4}\right)}{\left(9-99 k+320 k^{2}-256 k^{3}\right)^{2}}<0
\end{aligned}
$$

$C D$

$$
\begin{aligned}
W_{C D}= & \frac{3 \cdot\left(-1+c^{0}\right)^{2} \cdot(4-5 k)^{2} \cdot k \cdot(-12+25 k)}{\left(24-140 k+125 k^{2}\right)^{2}}+\frac{\left(-1+c^{0}\right)^{2} \cdot(6-5 k)^{2} \cdot k \cdot(-16+25 k)}{\left(24-140 k+125 k^{2}\right)^{2}} \\
& +\frac{1}{2}\left(\frac{10 \cdot\left(1-c^{0}\right) \cdot k \cdot(-9+10 k)}{24-140 k+125 k^{2}}\right)^{2}=\frac{2 \cdot\left(1-c^{0}\right)^{2} \cdot k \cdot\left(-576+4275 k-7400 k^{2}+3750 k^{3}\right)}{\left(24-140 k+125 k^{2}\right)^{2}} \\
W_{B} & -W_{C D}= \\
& -\frac{\left(1-c^{0}\right)^{2} \cdot k \cdot\left(5184-63018 k-248688 k^{2}-339900 k^{3}-113075 k^{4}+45000 k^{5}\right)}{\left(72-804 k+2615 k^{2}-2000 k^{3}\right)^{2}}<0
\end{aligned}
$$




\section{Comparative statics:}

\section{Total quantity}

The overall output is decreasing with innovation costs in all cases.

$$
\begin{aligned}
& \frac{\partial X_{B}}{\partial k}=\frac{\partial}{\partial k}\left(3 \cdot \frac{4 \cdot\left(1-c^{0}\right) \cdot k}{16 k-3}\right)=12 \cdot \frac{-1+c^{0}}{(3-16 k)^{2}}<0 \\
& \frac{\partial X_{S S R}}{\partial k}=\frac{\partial}{\partial k}\left(2 \cdot \frac{3 \cdot\left(1-c^{0}\right) \cdot k}{9 k-2}\right)=6 \cdot \frac{-1+c^{0}}{(2-9 k)^{2}}<0 \\
& \frac{\partial X_{D}}{\partial k}=\frac{\partial X_{J V}}{\partial k}=\frac{\partial}{\partial k}\left(\frac{2 \cdot\left(1-c^{0}\right) \cdot k \cdot(-5+6 k)}{3-17 k+16 k^{2}}\right)=2 \cdot \frac{\left(-1+c^{0}\right) \cdot\left(15-36 k+22 k^{2}\right)}{\left(3-17 k+16 k^{2}\right)^{2}}<0 \\
& \frac{\partial X_{C D}}{\partial k}=\frac{\partial}{\partial k}\left(\frac{10 \cdot\left(1-c^{0}\right) \cdot k \cdot(-9+10 k)}{24-140 k+125 k^{2}}\right)=10 \cdot \frac{\left(-1+c^{0}\right) \cdot\left(216-480 k+275 k^{2}\right)}{\left(24-140 k+125 k^{2}\right)^{2}}<0
\end{aligned}
$$

\section{Profits}

Differentiating firms' profits in the symmetric cases and outsiders' profits with respect to innovation costs leads to:

$$
\begin{aligned}
\frac{\partial \pi_{B}^{*}}{\partial k} & =\frac{\partial}{\partial k}\left(\frac{k \cdot\left(1-c^{0}\right)^{2} \cdot(-9+16 k)}{(3-16 k)^{2}}\right)=3 \cdot\left(-1+c^{0}\right)^{2} \cdot \frac{9+16 k}{(-3+16 k)^{3}}>0 \\
\frac{\partial \pi_{S S R}^{*}}{\partial k} & =\frac{\partial}{\partial k}\left(\frac{\left(1-c^{0}\right)^{2} \cdot k \cdot(-4+9 k)}{(2-9 k)^{2}}\right)=8 \cdot\left(-1+c^{0}\right)^{2} \cdot \frac{1}{(-2+9 k)^{3}}>0 \\
\frac{\partial \pi_{O, D}^{*}}{\partial k} & =\frac{\partial}{\partial k}\left(\frac{\left(-1+c^{0}\right)^{2}(-1+k)^{2} \cdot k \cdot(-9+16 k)}{\left(3-17 k+16 k^{2}\right)^{2}}\right) \\
& =\left(-1+c^{0}\right)^{2} \frac{-27+51 k+63 k^{2}-199 k^{3}+112 k^{4}}{\left(3-17 k+16 k^{2}\right)^{3}}>0 \\
\frac{\partial \pi_{O, C D}^{*}}{\partial k} & =\frac{\partial}{\partial k}\left(\frac{\left(-1+c^{0}\right)^{2} \cdot(6-5 k)^{2} \cdot k \cdot(-16+25 k)}{\left(24-140 k+125 k^{2}\right)^{2}}\right) \\
& =4 \cdot\left(-1+c^{0}\right)^{2} \cdot \frac{-3456+2160 k+19800 k^{2}-34750 k^{3}+15625 k^{4}}{\left(24-140 k+125 k^{2}\right)^{3}}>0
\end{aligned}
$$

Thus, these firms benefit from increasing innovation costs.

On the other hand, the derivative of insider's profit in case D (JV) and CD is negative and therefore they suffer losses from higher innovation costs: 


$$
\begin{aligned}
\frac{\partial \pi_{I, D}^{*}}{\partial k} & =\frac{\partial}{\partial k}\left(\frac{\left(-1+c^{0}\right)^{2}(3-4 k)^{2} \cdot k \cdot(-1+2 k)}{\left(3-17 k+16 k^{2}\right)^{2}}\right) \\
& =-\left(-1+c^{0}\right)^{2} \frac{-27-99 k+144 k^{2}-128 k^{3}+64 k^{4}}{\left(3-17 k+16 k^{2}\right)^{3}}<0 \\
\frac{\partial \pi_{I, C D}^{*}}{\partial k} & =\frac{\partial}{\partial k}\left(\frac{3 \cdot\left(-1+c^{0}\right)^{2} \cdot(4-5 k)^{2} \cdot k \cdot(-12+25 k)}{\left(24-140 k+125 k^{2}\right)^{2}}\right) \\
& =-12 \cdot\left(-1+c^{0}\right)^{2} \cdot \frac{1152-3840 k+5400 k^{2}-5500 k^{3}+3125 k^{4}}{\left(24-140 k+125 k^{2}\right)^{3}}<0
\end{aligned}
$$

\section{Optimal investment and quantities with integration problems}

\section{$S S R$}

Optimal quantities in an asymmetric Duopoly are:

$$
x_{i, S S R}^{*}=\frac{1-2 c_{i}+c_{j}}{3},
$$

leading to the profit function depending on investments in innovation:

$$
\begin{gathered}
\pi_{A, S S R}^{*}\left(c_{A}\right)=\left(\frac{1-2 c_{A}+c_{B}}{3}\right)^{2}-K\left(c_{A}\right)=x_{A}^{*}\left(c_{A}\right)^{2}-\alpha \cdot k \cdot\left(c_{A}-c^{0}\right)^{2} \\
\pi_{B, S S R}^{*}\left(c_{B}\right)=\left(\frac{1-2 c_{B}+c_{A}}{3}\right)^{2}-K\left(c_{B}\right)=x_{B}^{*}\left(c_{B}\right)^{2}-k \cdot\left(c_{B}-c^{0}\right)^{2},
\end{gathered}
$$

where A indicates the merged company and B the outsider.

This yields the first order conditions:

$$
\begin{aligned}
& \frac{\partial \pi_{A}}{\partial c_{A}}=-\frac{4}{9}\left(1-2 c_{A}+c_{B}\right)-2 \alpha \cdot k \cdot\left(c_{A}-c^{0}\right) \stackrel{!}{=} 0 \\
& \frac{\partial \pi_{B}}{\partial c_{B}}=-\frac{4}{9}\left(1-2 c_{B}+c_{A}\right)-2 k \cdot\left(c_{B}-c^{0}\right) \stackrel{!}{=} 0
\end{aligned}
$$

Solving for $c_{A}$ and $c_{B}$ yields:

$$
\begin{aligned}
& c_{A}=-\frac{-4+6 k+6 c^{0} \cdot k+12 \alpha \cdot c^{0} \cdot k-27 \alpha \cdot c^{0} \cdot k^{2}}{4-12 k-12 \alpha \cdot k+27 \alpha \cdot k^{2}} \\
& c_{B}=-\frac{-4+6 \alpha \cdot k+12 c^{0} \cdot k+6 \alpha \cdot c^{0} \cdot k-27 \alpha \cdot c^{0} \cdot k^{2}}{4-12 k-12 \alpha \cdot k+27 \alpha \cdot k^{2}}
\end{aligned}
$$

This leads to the optimal profit: 


$$
\begin{aligned}
& \pi_{A}=\frac{a \cdot\left(1-c^{0}\right)^{2} \cdot k \cdot(2-3 k) \cdot(-4+9 \alpha \cdot k)^{2}}{\left(4-12 k-12 \alpha \cdot k+27 \alpha \cdot k^{2}\right)^{2}} \\
& \pi_{B}=\frac{\left(1-c^{0}\right)^{2} \cdot k \cdot(-4+9 k) \cdot(2-3 \alpha \cdot k)^{2}}{\left(4-12 k-12 \alpha \cdot k+27 \alpha \cdot k^{2}\right)^{2}}
\end{aligned}
$$

One easily verifies $c_{A}=c_{B}$ and $\pi_{A}=\pi_{B}$ for $a=1$.

Inserting the optimal marginal costs in equation for optimal quantities and adding up these quantities yields the total quantity:

$$
X_{S S S, \alpha}^{*}=\frac{3 k \cdot(-1+\alpha \cdot(-1+3 k))}{4-12 k-12 \alpha \cdot k+27 \alpha \cdot k^{2}}
$$

The resulting social surplus is:

$$
\begin{aligned}
W_{S S R} & =\frac{1}{2} \cdot\left(X_{S S R, \alpha}^{*}\right)^{2}+\pi_{A}+\pi_{B} \\
& =\frac{k\left(-8+27 k+9 \alpha^{2} \cdot k \cdot\left(3-14 k+18 k^{2}\right)-2 \alpha \cdot\left(4-33 k+63 k^{2}\right)\right)}{2 \cdot\left(4-12 k-12 \alpha \cdot k+27 \alpha \cdot k^{2}\right)^{2}}
\end{aligned}
$$

D

Optimal quantities in an asymmetric Stackelberg market are

$$
x_{M}^{*}=\frac{1-2 c_{M}+c_{O}}{2}
$$

of the merged company and

$$
x_{O}^{*}=\frac{1-3 c_{O}+2 c_{M}}{4}
$$

of the outsider.

Resulting profits are:

$$
\begin{gathered}
\pi_{I, D}^{*}\left(c_{M}\right)=\frac{\left(1-2 c_{M}+c_{O}\right)^{2}}{8}-K\left(c_{M}\right)=\frac{\left(1-2 c_{M}+c_{O}\right)^{2}}{8}-\alpha \cdot k \cdot\left(c_{M}-c^{0}\right)^{2} \\
\pi_{O, D}^{*}\left(c_{O}\right)=\frac{\left(1+2 c_{M}-3 c_{O}\right)^{2}}{16}-K\left(c_{O}\right)=\frac{\left(1+2 c_{M}-3 c_{O}\right)^{2}}{16}-k \cdot\left(c_{O}-c^{0}\right)^{2}
\end{gathered}
$$

This yields the first order conditions:

$$
\begin{aligned}
& \frac{\partial \pi_{I, D}^{*}}{\partial c_{M}}=-\frac{1}{2}\left(1-2 c_{M}+c_{O}\right)-2 \alpha \cdot k \cdot\left(c_{M}-c^{0}\right)=0 \\
& \frac{\partial \pi_{O, D}^{*}}{\partial c_{O}}=-\frac{3}{8}\left(1+2 c_{M}-3 c_{O}\right)-2 k \cdot\left(c_{O}-c^{0}\right)=0
\end{aligned}
$$


Solving for $c_{M}$ and $c_{O}$ leads to:

$$
\begin{aligned}
& c_{M}^{*}=\frac{3-\left(4+(4+9 \alpha) \cdot c^{0}\right) \cdot k+16 \alpha \cdot k^{2} \cdot c^{0}}{3-(8+9 \alpha) \cdot k+16 \alpha \cdot k^{2}} \\
& c_{O}^{*}=\frac{3-8 k \cdot c^{0}+\alpha \cdot k \cdot\left(-3+2 c^{0} \cdot(-3+8 k)\right)}{3-(8+9 \alpha) \cdot k+16 \alpha \cdot k^{2}}
\end{aligned}
$$

Thus, optimal profits are:

$$
\begin{aligned}
& \pi_{I, D}^{*}=\frac{\alpha \cdot\left(-1+c^{0}\right)^{2} \cdot k \cdot(3-4 k)^{2} \cdot(-1+2 \alpha \cdot k)}{\left(3-(8+9 \alpha) \cdot k+16 \alpha \cdot k^{2}\right)^{2}} \\
& \pi_{O, D}^{*}=\frac{\left(-1+c^{0}\right)^{2} \cdot k \cdot(-9+16 k) \cdot(-1+\alpha \cdot k)^{2}}{\left(3-(8+9 \alpha) \cdot k+16 \alpha \cdot k^{2}\right)^{2}}
\end{aligned}
$$

Total output in case D is:

$$
X_{D}^{*}=x_{M}^{*}+x_{O}^{*}=\frac{2 \cdot\left(1-c^{0}\right) \cdot k \cdot(-2+\alpha \cdot(-3+6 k))}{3-(8+9 \alpha) \cdot k+16 \alpha \cdot k^{2}}
$$

Social Surplus is:

$$
\begin{aligned}
W_{D} & =\frac{1}{2}\left(X_{D}^{*}\right)^{2}+\pi_{I, D}^{*}+\pi_{O, D}^{*} \\
& =\frac{3 \cdot\left(1-c^{0}\right)^{2} \cdot k \cdot(-3+8 k+\alpha \cdot(-3+k \cdot(22-32 k+\alpha \cdot(12+k \cdot(-43+40 k)))))}{\left(3-(8+9 \alpha) \cdot k+16 \alpha \cdot k^{2}\right)^{2}}
\end{aligned}
$$

\section{CD}

Using the profit functions derived in section 2.4 with changed innovation cost functions for the insider

$$
\begin{gathered}
\pi_{I, C D}^{*}=\frac{3}{25}\left(1+c_{o}-2 c_{m}\right)^{2}-\alpha \cdot k \cdot\left(c_{m}-c^{0}\right)^{2} \\
\pi_{O, C D}^{*}=\frac{1}{25}\left(1-4 c_{o}+3 c_{m}\right)^{2}-k \cdot\left(c_{o}-c^{0}\right)^{2},
\end{gathered}
$$

we derive the first order conditions:

$$
\begin{aligned}
& \frac{\partial \pi_{I, C D}^{*}}{\partial c_{m}}=-\frac{12}{25} \cdot\left(1+c_{o}-2 c_{m}\right)-2 \alpha \cdot k \cdot\left(c_{m}-c^{0}\right)=0 \\
& \frac{\partial \pi_{O, C D}^{*}}{\partial c_{o}}=-\frac{8}{25} \cdot\left(1-4 c_{o}+3 c_{m}\right)-2 k \cdot\left(c_{o}-c^{0}\right)=0
\end{aligned}
$$

Solving for $c_{m}$ and $c_{o}$ leads to 


$$
\begin{gathered}
c_{m}^{*}=\frac{24-30 k-30 k \cdot c^{0}-80 \alpha \cdot k \cdot c^{0}+125 \alpha \cdot k^{2} \cdot c^{0}}{24-60 k-80 \alpha \cdot k+125 \alpha \cdot k^{2}} \\
c_{o}^{*}=\frac{24-20 \alpha \cdot k-60 k \cdot c^{0}-60 \alpha \cdot k \cdot c^{0}+125 \alpha \cdot k^{2} \cdot c^{0}}{24-60 k-80 \alpha \cdot k+125 \alpha \cdot k^{2}}
\end{gathered}
$$

This yields the optimal profits:

$$
\begin{aligned}
& \pi_{I, C D}^{*}=\frac{3 \alpha \cdot\left(-1+c^{0}\right)^{2} \cdot(4-5 k)^{2} \cdot k \cdot(-12+25 \alpha \cdot k)}{\left(24-20 \cdot(3+4 \alpha) k+125 \alpha \cdot k^{2}\right)^{2}} \\
& \pi_{O, C D}^{*}=\frac{\left(-1+c^{0}\right)^{2} \cdot(-16+25 k) \cdot k \cdot(6-5 \alpha \cdot k)}{\left(24-20 \cdot(3+4 \alpha) k+125 \alpha \cdot k^{2}\right)^{2}}
\end{aligned}
$$

Total output in case CD is:

$$
X_{C D}^{*}=x_{m}^{*}+x_{o}^{*}=\frac{10 \cdot\left(1-c^{0}\right) \cdot k \cdot(-3+2 \alpha \cdot(-3+5 k))}{24-20 \cdot(3+4 \alpha) \cdot k+125 \alpha \cdot k^{2}}
$$

Social Surplus is:

$$
\begin{aligned}
& W_{C D}=\frac{1}{2}\left(X_{C D}^{*}\right)^{2}+\pi_{I, C D}^{*}+\pi_{O, C D}^{*} \\
& =\frac{2 \cdot\left(1-c^{0}\right)^{2} \cdot k \cdot(9 \cdot(-32+75 k))+50 \cdot \alpha^{2} k \cdot\left(30-94 k+75 k^{2}\right)-12 \alpha \cdot\left(24-175 k+225 k^{2}\right)}{\left(24-20(3+4 \alpha) \cdot k+125 \alpha \cdot k^{2}\right)^{2}}
\end{aligned}
$$

